Article

\title{
Experimental Study of the Fatigue Performance of the Bonding Surfaces and Load-Bearing Capacity of a Large-Scale Severely Damaged Hollow Slab Strengthened by CFRP
}

\author{
Hao $\mathrm{Hu}^{1,2}$, Chuan-Zhi Dong ${ }^{3, *(\mathbb{C})}$, Jiji Wang ${ }^{1,2}$ and Jiaqi Chen ${ }^{1,2}$ \\ 1 Zhejiang Provincial Key Lab for Detection and Maintenance Technology of Road and Bridge, \\ Hangzhou 310023, China; hhu@zjjtkyy.com (H.H.); wjj@zjjtkyy.com (J.W.); chjq@zjjtkyy.com (J.C.) \\ 2 Zhejiang Scientific Research Institute of Transport, Hangzhou 310023, China \\ 3 Department of Civil, Environmental, and Construction Engineering, University of Central Florida, \\ Orlando, FL 32816, USA \\ * Correspondence: ceczdong@knights.ucf.edu
}

check for updates

Citation: Hu, H.; Dong, C.-Z.; Wang, J.; Chen, J. Experimental Study of the Fatigue Performance of the Bonding Surfaces and Load-Bearing Capacity of a Large-Scale Severely Damaged Hollow Slab Strengthened by CFRP. Sustainability 2021, 13, 12179. https:// doi.org/10.3390/su132112179

Academic Editors: Sanghyo Lee and Sungkon Moon

Received: 5 October 2021

Accepted: 1 November 2021

Published: 4 November 2021

Publisher's Note: MDPI stays neutral with regard to jurisdictional claims in published maps and institutional affiliations.

Copyright: (c) 2021 by the authors. Licensee MDPI, Basel, Switzerland. This article is an open access article distributed under the terms and conditions of the Creative Commons Attribution (CC BY) license (https:/ / creativecommons.org/licenses/by/ $4.0 /)$.

\begin{abstract}
In recent years, carbon fiber reinforced polymer (CFRP) has been widely used in bridge repair, retrofitting, rehabilitation and strengthening to improve the bearing capacity. Although many studies have been conducted to explore the strengthening efficiencies of CFRP, the test specimens were small and the results were difficult to apply to full-scale bridges. Investigations into the strengthening effects of CFRP on real life structures rely on field load tests (without damaging the structures), making it difficult to understand actual improvements in load carrying capacity and strengthening effect. Moreover, there have been few experimental studies on the fatigue performances of CFRP-strengthened structures, especially on the large-scale structures with real wheel moving loads. In this study, the feasibility and efficiency of CFRP strengthening and repair was investigated on a large-scale, prestressed concrete hollow slab decommissioned from a real-life concrete bridge. The hollow slab was first put through a destructive test to test the ultimate load-bearing capacity. Then, CFRP strips were installed on the surface of the severely damaged slab to repair and strengthen it. Fatigue load test—including the moving load test and single point sinusoidal load-and loadbearing capacity tests were conducted on the CFRP-strengthened hollow slab after the destructive test to evaluate the strengthening performance. This study could help us to understand the actual load-bearing capacities of severe damaged concrete structures strengthened by CFRP, reduce waste, save resources and improve the utilization of our infrastructures.
\end{abstract}

Keywords: carbon fiber reinforced polymer; hollow slab; bridge repair; fatigue; adhesive failure

\section{Introduction}

With rising socioeconomic development and increasing demand for transportation over the years, over the last several decades, many bridges have been constructed and put into service. Since bridges play critical roles in our traffic systems, ensuring their safety and normal operation is critical to the management and maintenance of infrastructures [1]. Due to environmental effects and external loads (such as temperature effect, chloride ions invasion, scouring, increasing traffic loads and occasional impact loads or collisions, etc.), many bridges have shown increasing deficiencies over time and become damaged. According to the 2021 Report Card for America's Infrastructure [2], published by American Society of Civil Engineers (ASCE), 7.5\% of the bridges in US are considered structurally deficient. It would cause around $\$ 125$ billion to improve the structural conditions of the deficient bridges. Bridge rehabilitation, repair and retrofitting could put a heavy burden on the budget of the bridge owners and managing departments. Moreover, as the bridges are aging and current traffic loads are increasing, in terms of load cycles and weights of vehicles, bridges that were designed and constructed in past decades may not satisfy the 
requirements of the latest safety and operation standards or regulations [3]. These issues can result in early intervention, load permit post, costly replacement, and early demolition. It would waste resources and harm the development of sustainable societies [4,5]. A similar situation exists in other countries all over the world. It is essential to develop cost-effective and performance-efficient bridge rehabilitation strategies and approaches to improve bridge conditions and increase their carrying capacity. Prestressed concrete hollow slab bridges have grown very popular in highway bridge systems, largely due to their many advantages, including easy construction, simple structure, small section height and low cost of materials. Similarly, the rehabilitation and strengthening of hollow slab bridges has become a significant topic in research studies and engineering practices. An efficient and effective approach for the rehabilitation and strengthening of these bridges could not only improve the status of the bridge itself, but also be beneficial for the promotion of concepts of sustainability worldwide.

Generally, in hollow slab bridges, the adjacent slabs are connected using hinge joints to ensure that the multiple slab components work in a synergistic manner. Each slab component is designed to bear a certain percentage of live loads according to the calculation of lateral load distribution [6]. However, due to hinge joint damage (induced by construction deficiencies, heavy trucks, deficient design, etc.), the lateral connections between the adjacent slabs are degraded and even broken. This results in the single slab bearing phenomenon, meaning that the single slab may carry entire wheel loads, potentially greatly exceeding the designated load-carrying capacity. Under continuous vehicle loading, slab components experiencing the single slab bearing phenomenon are prone to damage. Improving lateral connection could increase the load-bearing capacity, but for slabs with severe damage, it is likelier that they will be demolished and rebuilt, per general practices. However, in real engineering projects, there are large amount of bridge components which have not been so damaged as to warrant demolition. It is a waste of resources to decommission them and rebuild new ones. In fact, the potential load-carrying capacities of damaged components can be increased and extended. For hollow slab components with damage induced by overloading, carrying capacity can be improved through external reinforcement or strengthening approaches. In this way, the strengthened bridge components could remain in service.

In engineering practices, there are many approaches for the rehabilitation and strengthening of concrete bridges. Concrete jacketing is one of the most popular approaches. In concrete jacketing, new layers of concrete and other strengthening elements are used to cover the damaged area [7]. Concrete jacketing can effectively improve the stiffness of damaged concrete components of bridges and increase their carrying capacity. However, the drawbacks of concrete jacketing-such as possible bridge closure, increases in the weight of the bridge and the size of the structures, and high operation costs-limit the wide application of this technique in practice. Another strengthening approach used for concrete involves the installation of bonded steel plates on the surface of the concrete to increase the load-bearing capacity. This approach does not significantly increase the size of the original structure, but the strength of the bonding between the steel plate and the concrete may limit strengthening effect. Additionally, steel plates are susceptible to corrosion. Other strengthening approaches, i.e., the use of shape memory alloy [8,9] and external prestressed tendons $[10,11]$, are also good for bridge rehabilitation, repair and retrofit, but the implementations and construction procedures for these are very complicated and incur significant time, cost and labor.

In recent years, carbon fiber reinforced polymer (CFRP) has been widely used in bridge repair, retrofitting, rehabilitation and strengthening to improve the bearing capacity [12-15]. The advantages of CFRP include the low cost, high strength to weight ratio, resistance to chemicals, excellent corrosion resistance, good fatigue strength, and high durability [15-18]. The fact that they are lightweight with high strength and high stiffness means that CFRPs need less equipment and resources during the bridge strengthening and repairing, permitting fast fabrication, easy installation with reasonable life cycle costs and 
low levels of waste production $[19,20]$. Through the application of prestress into CFRPs, the load-carrying capacity of deteriorated bridges could be partially or even fully recovered [21]. Existing experimental and theoretical research $[22,23]$ has shown that applying CFRP as a retrofitting approach could also efficiently improve the seismic performance of existing structures. Glass fiber reinforced polymer (GFRP) is very similar to CFRP and even more cost-effective. However, CFRP can provide higher tensile strength and stiffness. High strength CFRP needs less resin and results in a more cost-effective total solution $[24,25]$. CFRP materials have been widely applied in different types of structural components, according to the functions. These include components such as beams [26-28], slabs [17,29], columns [16,30], and walls [25]. For beam or slab components, CFRP materials can be fabricated into different patterns, including CFRP strip [29], plate [31,32], rod [33], rebar [34], rope [35], and multiple-surface wrap [36]. Beam and slab components mainly bear the bending and shear forces, while CFRP strip and plate are very popular choices for the strengthening purposes of these component types. The CFRP strip/plate can be installed on the surface of the components to provide external strengthening effects [28] or be mounted near the surface [37].

Over the last three decades, many studies have systematically investigated the strengthening efficiencies of CFRP, including mounting approaches, bonding effects, failure modes, adhesive methods, and ductility under different types loads and factors. Triantafillou et al. [38] strengthened a test beam with prestressed CFRP and, through comparative experiments, found that strengthening the beam with CFRP improved the load-carrying capacity 3-4 times over. Additionally, they observed that adding prestress could prevent the growth of cracks. Quantril and Hollaway [39] conducted comparative tests on a beam with prestressed CFRP and unstressed CFRP and found that CFRP plates with and without prestress both improved the load carry capacity. However, strengthening the beam with prestressed CFRP led to a more efficient performance. Wright et al. [40] found that prestressed CFRP sheets could reduce crack widths and delay the onset of cracking effectively. Moshiri et al. [41] investigated the flexural strengthening effects of RC slabs with non-prestressed and prestressed CFRP strips using the externally bonded reinforcement on grooves (EBROG) method; they found that the two proposed strategies improved the strengthening effects by $34 \%$ and $77 \%$, respectively, compared to the conventional method using only externally bonded reinforcement and no prestressing. Charlot et al. [42] investigated the bonding failure mechanism of CFRP/concrete interface, conducting a series of double shear tests under low-cycle fatigue loading. They developed an analytical model to predict the lifetime of a CFRP/concrete interface. Zhou et al. [43] explored the behavior of CFRP-to-concrete bonded joints under fatigue cyclic loading and found that, under fatigue loads, multiple factors, such as cohesion failure within concrete, cohesion failure within adhesive, and interlaminar failure within CFRP laminate, could cause the failure of CFRP-to-concrete bonded joints.

Although many research studies were conducted to explore the strengthening efficiency of CFRP for concrete structures, there were some limitations, which need to be carefully addressed. First, in previous experimental studies on CFRP strengthening effects, the test specimens were small and, due to scale effects, it may be difficult to directly apply the experiences and strengthening strategies from small specimen experiments to full-scale bridges. The investigation of strengthening effects of CFRP on real life structures relies on field load tests without damaged bridge structures. It is difficult, therefore, to understand the real improvement of load carrying capacity and strengthening effects. Second, few experimental studies have been conducted on fatigue performances of CFRP-strengthened beams. Furthermore, without getting into details of the fatigue failure mechanism, most of the research mainly focused on the structural failure of the whole beam induced by fatigue loads. In real-life applications, the adhesive failure of CFRP strips under fatigue loads is critical; after adhesive failure, the tension force between CFRP strips and concrete between the anchor ends. In addition, the existing fatigue tests were single shear tests (pull-out test) or double shear test [42], neither of which are bending fatigue tests. In particular, there 
have been very few research studies on large-scale fatigue tests and cases involving beams with large numbers of cracks. Moreover, in experimental studies to date, there has been a lack of effective approaches or test set-ups to simulate actual wheel loads.

In this study, a decommissioned prestressed concrete hollow slab was taken as an example to investigate the strengthening efficiencies of CFRP, including its adhesive performance under various types of fatigue loads and its bearing capacity. The slab was removed from a bridge with a service life of 22 years. In this study, the concrete hollow slab was first put through a destructive test to test its ultimate strength. Then, CFRP strips were installed on the surface of the slab to repair and strengthen it. Subsequently, fatigue load tests and load-bearing capacity tests were conducted using a large-scale test machine which was able to simulate various types of load configurations and real wheel loads to investigate the strengthening capacities of CFRP.

\section{Experimental Preparation}

\subsection{Test Specimen}

\subsubsection{A Decommissioned Prestressed Concrete Hollow Slab}

The decommissioned prestressed concrete hollow slab tested in this study was removed from a bridge with a service life of 22 years and transported to the laboratory of Zhejiang Scientific Research Institute of Transport, as shown in Figure 1. The hollow slab had a total span of $20 \mathrm{~m}$ and a concrete grade of C50. The bottom of the hollow slab was equipped with five bundles of cold-drawn, grade IV prestressed reinforcements with diameters of $25 \mathrm{~mm}$. The ends of the hollow slab were reinforced by $12 \mathrm{~mm}$ threaded rebars, and $8 \mathrm{~mm}$ plain round bars were used for construction. The cross-section dimensions of the hollow slab are marked in Figure 2a. The overall condition of the hollow slab was good and few initial vertical and diagonal cracks could be found in the web, as shown in Figure $2 b$. The detailed reinforcement layout of the prestressed concrete hollow slab is illustrated in Figure 3.

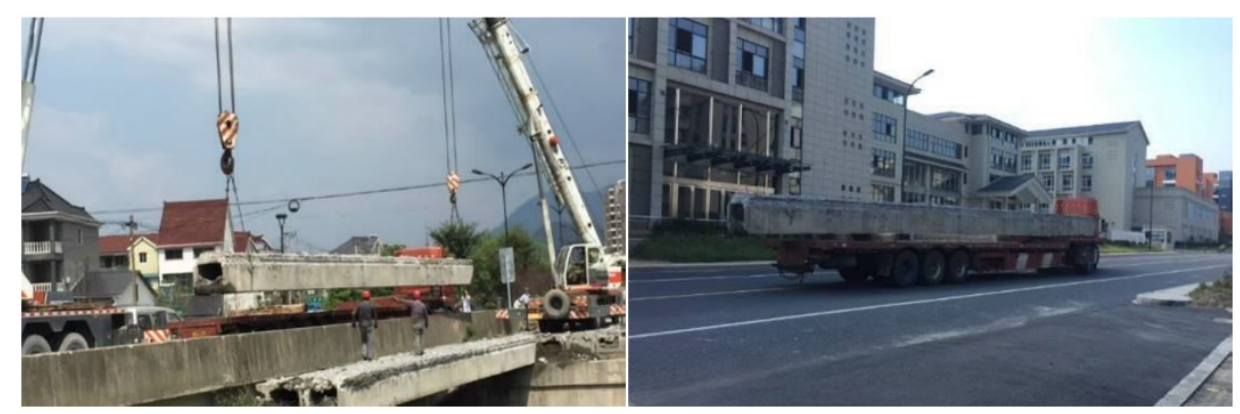

Figure 1. Hollow slab decommission and transportation.

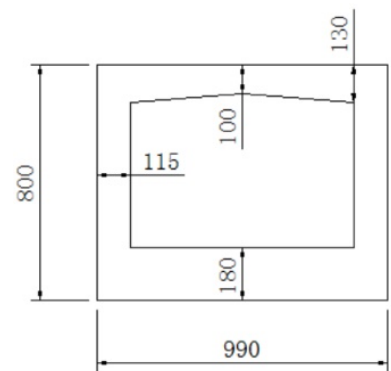

(a)

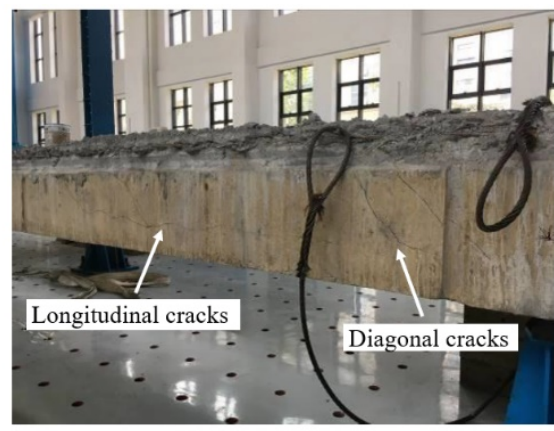

(b)

Figure 2. Dimension and condition of the slab: (a) cross-section dimensions (unit: $\mathrm{mm}$ ); (b) longitudinal and diagonal cracks in the web. 


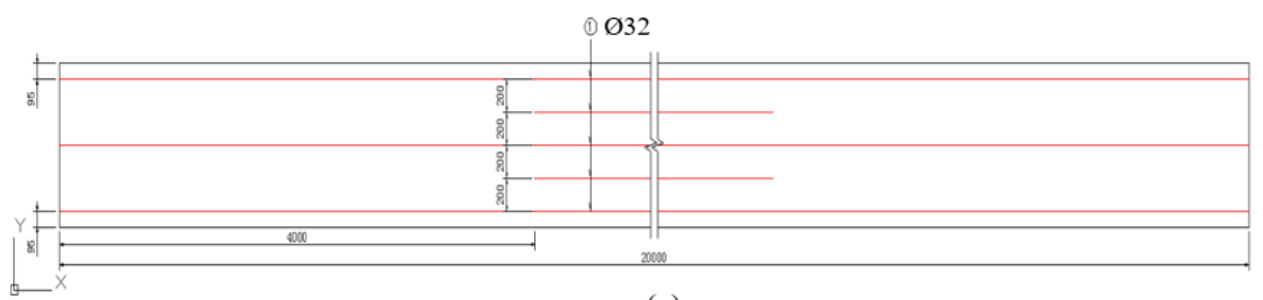

(a)

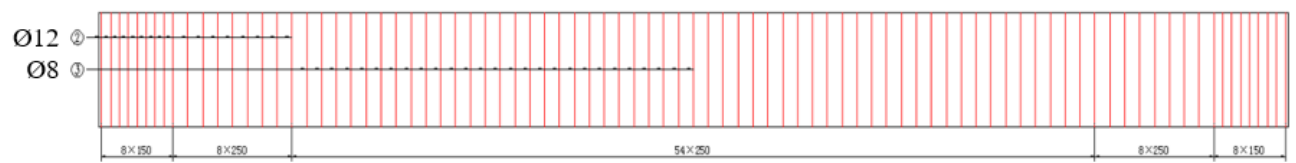

(b)

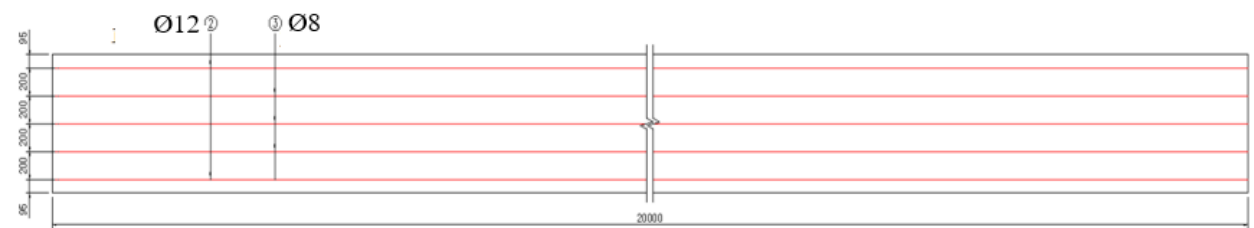

(c)

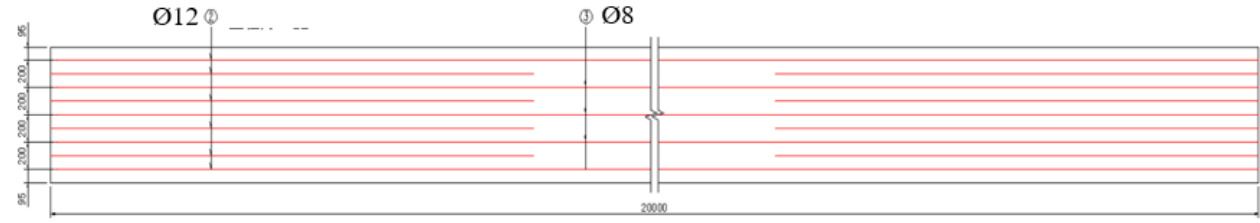

(d)

Figure 3. Layout of reinforcements in the prestressed concrete hollow slab (unit: $\mathrm{mm}$ ): (a) layout of prestressed reinforcements in bottom plate; (b) layout of rebars in web; (c) layout of rebars in bottom plate; (d) layout of rebars in top plate.

\subsubsection{Destructive Test}

To investigate the ultimate bearing capacity of the decommissioned prestressed concrete hollow slab and explore the CFRP strengthening efficiencies, a destructive test was done with a test machine made by a large-scale reaction frame and a hydraulic jack. The detailed load test set-up is shown in Figure 4.

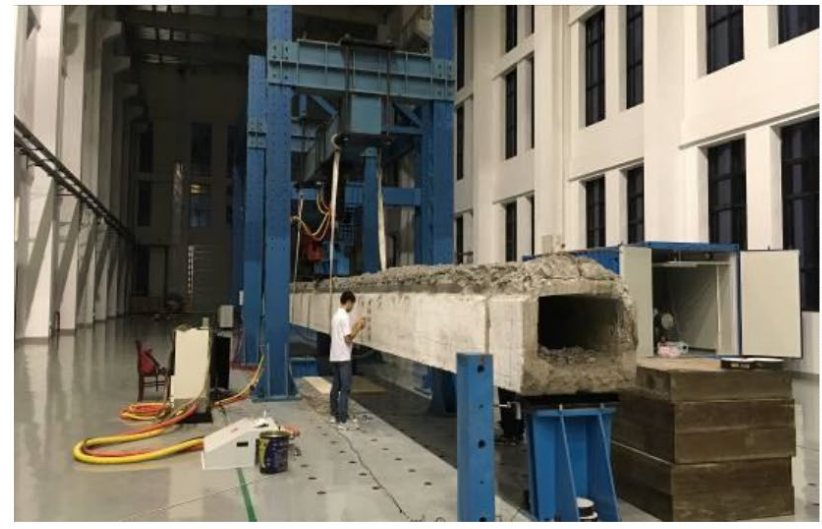

(a)

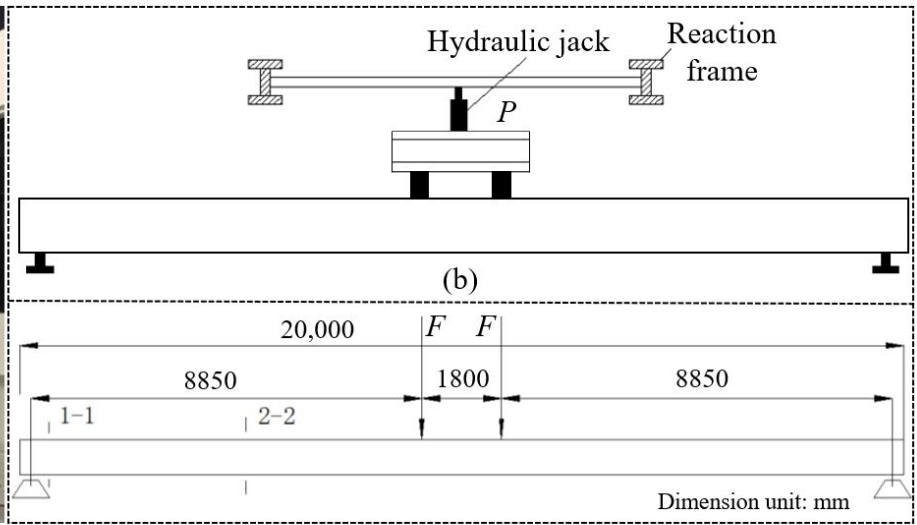

(c)

Figure 4. Load test set-up: (a) load test set-up in laboratory; (b) sketch of the load test set-up; (c) illustration of the load configuration. 
Strain gauges and displacement sensors were installed on the tested slab to monitor responses during the load test. The loading process began at $0 \mathrm{kN}$ and kept increasing until it reached the load step. The load steps were as follows: $0,20,40,60,80,100,110$, $120,140,160180,200,250,300,330,340,350 \mathrm{kN}$. The load value, $P$, refers to the load on the hydraulic jack, as shown in Figure $4 \mathrm{~b}$. At each load step, the crack status of the slab, strains, and displacements were recorded. It was observed that, when the control load was $350 \mathrm{kN}$, the maximum width of the vertical crack in the concrete of the tensile zone reached $1.53 \mathrm{~mm}$. According to the national standard of China, GB 50204-2015 [44], the test slab reached or exceeded the ultimate load-bearing capacity. The load process was stopped. The ultimate status of the slab was plastic failure of a balanced-reinforced beam. At the end of the destructive test, there were a total of 24 cracks in the concrete slab, including some some that went completely through the slab, as shown in Figure 5. The hollow slab was severely damaged during the destructive test. It should be noted that Figure 5a only shows the slab section from 6 to $16 \mathrm{~m}$. The ultimate bearing capacity of this beam, $350 \mathrm{kN}$, was much larger than the calculated value, $176.7 \mathrm{kN}$, which means that the tested slab had enough safety reserve. The maximum displacement at midspan was $142.2 \mathrm{~mm}$, smaller than one-fiftieth of the total span ( $L / 50, L$ is the total span length).

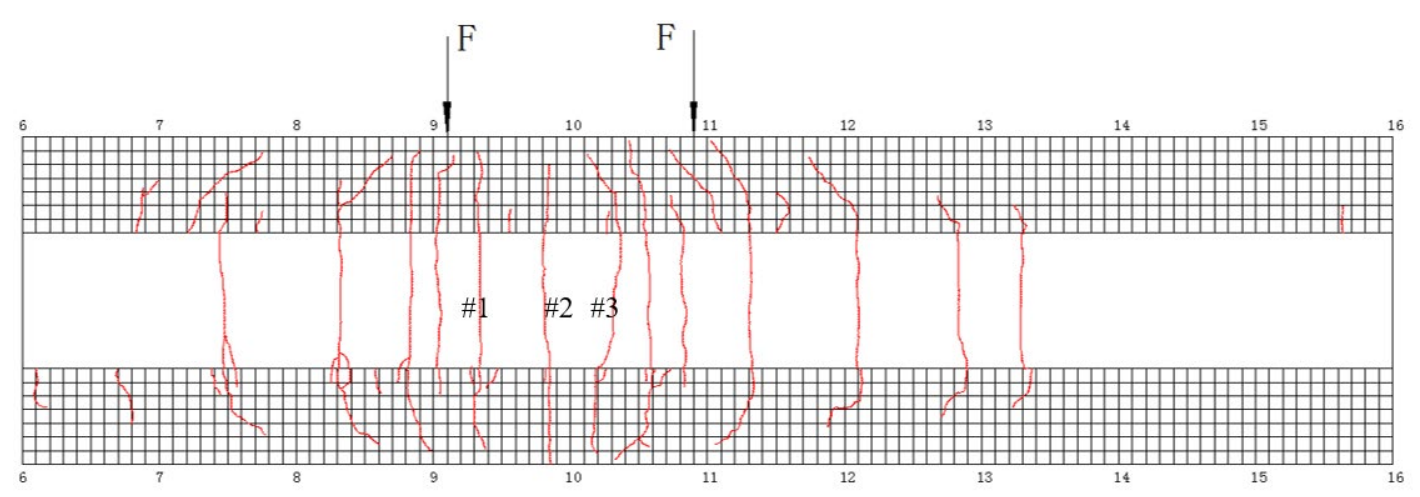

(a)

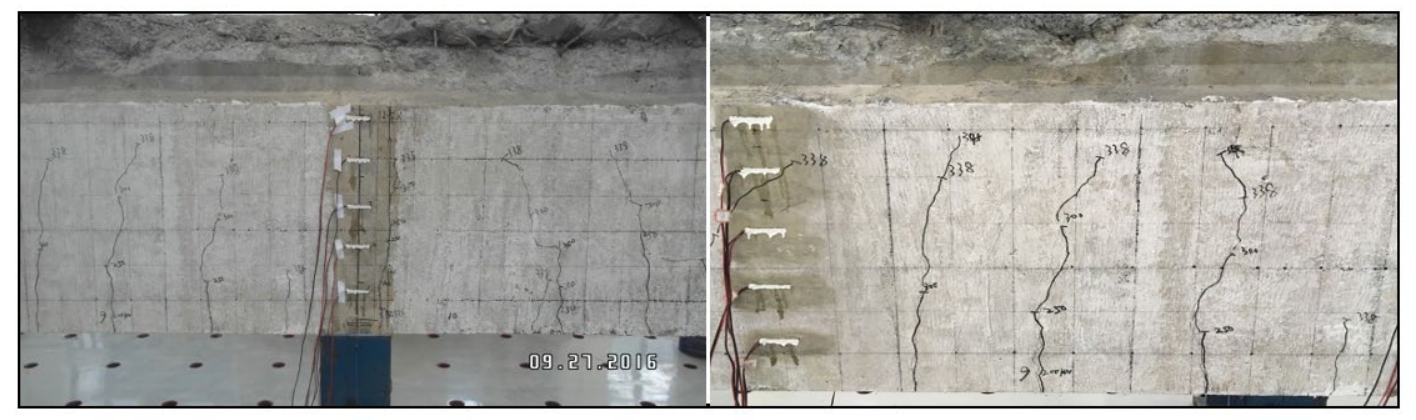

(b)

Figure 5. Distribution of cracks of the slab at the end of the destructive test: (a) distribution of cracks at the ultimate load status (the range of 6 to 16 meters); (b) typical cracks on concrete surface.

\subsection{CFRP Strengthening for Severely Damaged Slab}

To strengthen the severely damaged slab during the destructive test, prestressed CFRP strips sized $16,650 \mathrm{~mm}$ (length) $\times 50 \mathrm{~mm}$ (width) $\times 2 \mathrm{~mm}$ (thickness) were mounted on the bottom of the slab. The material properties of the installed CFRP strips are listed in Table 1. The layout of the installed prestressed CFRP strips is shown in Figure 6. Each CFRP strip had one tensile end anchorage and one fixed end anchorage. The tensioning device was installed on the tensile end anchorage and provided the prestress to the CFRP strips. The prestressed CFRP strips were bonded with adhesive and fixed with CFRP clamp plates. In each CFRP strip, the prestress force was equal to $200 \mathrm{kN}$, such that $600 \mathrm{kN}$ of force in total was added on the whole slab. Calculations indicated that, with the prestressed CFRP 
strips, the bending and bearing strength was improved by $18 \%$, compared to the original hollow slab before the destructive test.

Table 1. Material properties of the installed CFRP strips.

\begin{tabular}{cc}
\hline Technical Item & Value \\
\hline Tensile strength $(\mathrm{MPa})$ & $\geq 2400$ \\
Tensile modulus (GPa) & $\geq 160$ \\
Interlaminar shear strength $(\mathrm{MPa})$ & $\geq 50$ \\
Elongation rate $(\%)$ & $\geq 1.6$ \\
Tensile bonding strength with concrete $(\mathrm{MPa})$ & $\geq 2.5$ \\
Fiber percentage by volume $(\%)$ & $\geq 65$ \\
\hline
\end{tabular}

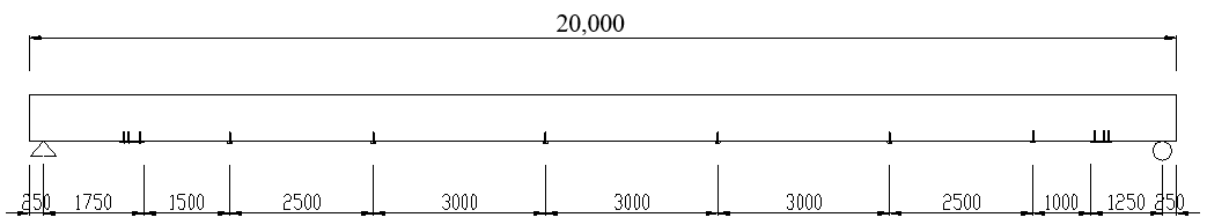

(a) Front view

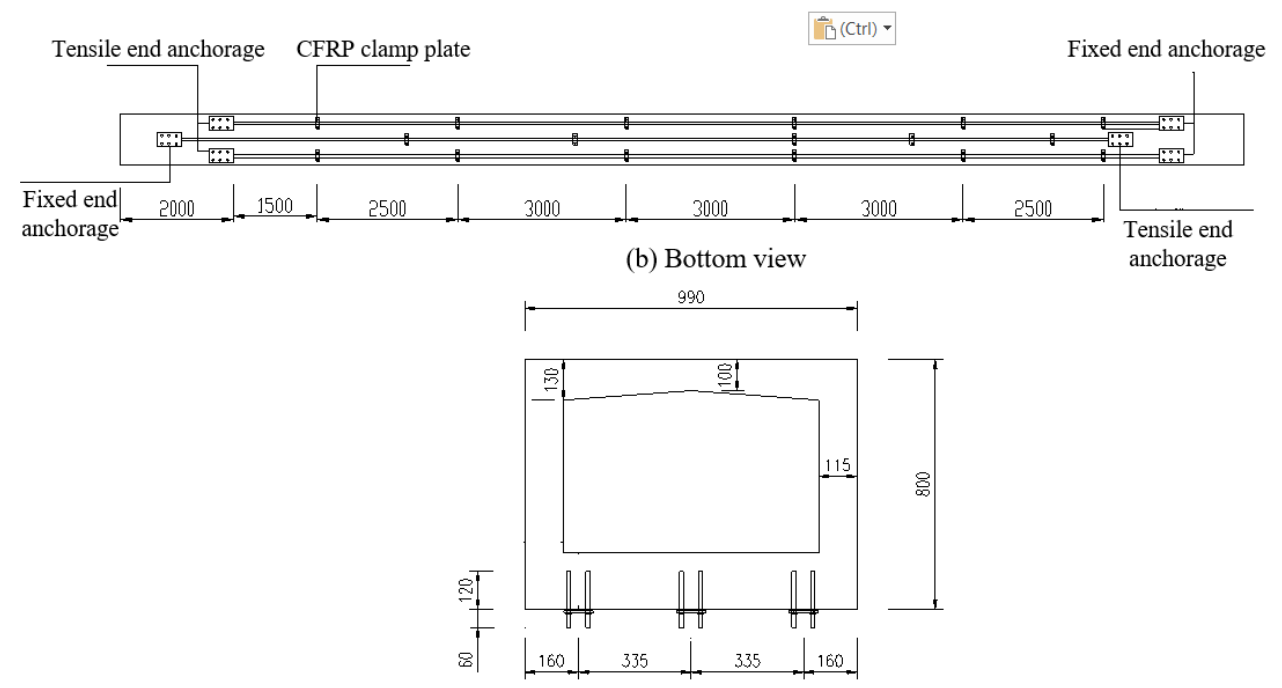

(c) Cross-section

Figure 6. Layout of the installed prestressed CFRP strips (unit: $\mathrm{mm}$ ).

\subsection{Test Machine}

To simulate the fatigue effect caused by actual vehicle loads, Zhejiang Scientific Research Institute of Transport conducted a four-year research and development (R\&D) project to build a wheel-moving fatigue test machine with a long moving range. The R\&D project included three stages. In the first stage (2014 to 2015), the basic structural members of the test machine, which included the reaction framework, wheel-moving machine, and guideway, were built. In the second stage (2016), the hydraulic horizontal movement system, lifting-lowering device, specimen transportation module, and data transmission module were integrated into this system, and the machine passed the debug test for durability and accuracy. In the third stage (2017 2018), the whole length of structural framework was extended from $10 \mathrm{~m}$ to $20 \mathrm{~m}$, achieving a great improvement of test applicability. Figure 7 shows the front view and side view of the wheel-moving fatigue test machine. The internal width of the third stage frame was $4 \mathrm{~m}$, which is one-half of the first stage frame. Due to the scale expansion, the fatigue test machine grew more adaptable to specimen variety with different scales. Wide bridge deck specimens can be placed in the first stage frame. Long bridge girder specimens can be placed in all frames. To achieve the 
whole frame loading, the longitudinal track-beam from the first stage would be positioned and joined with one from the third stage.

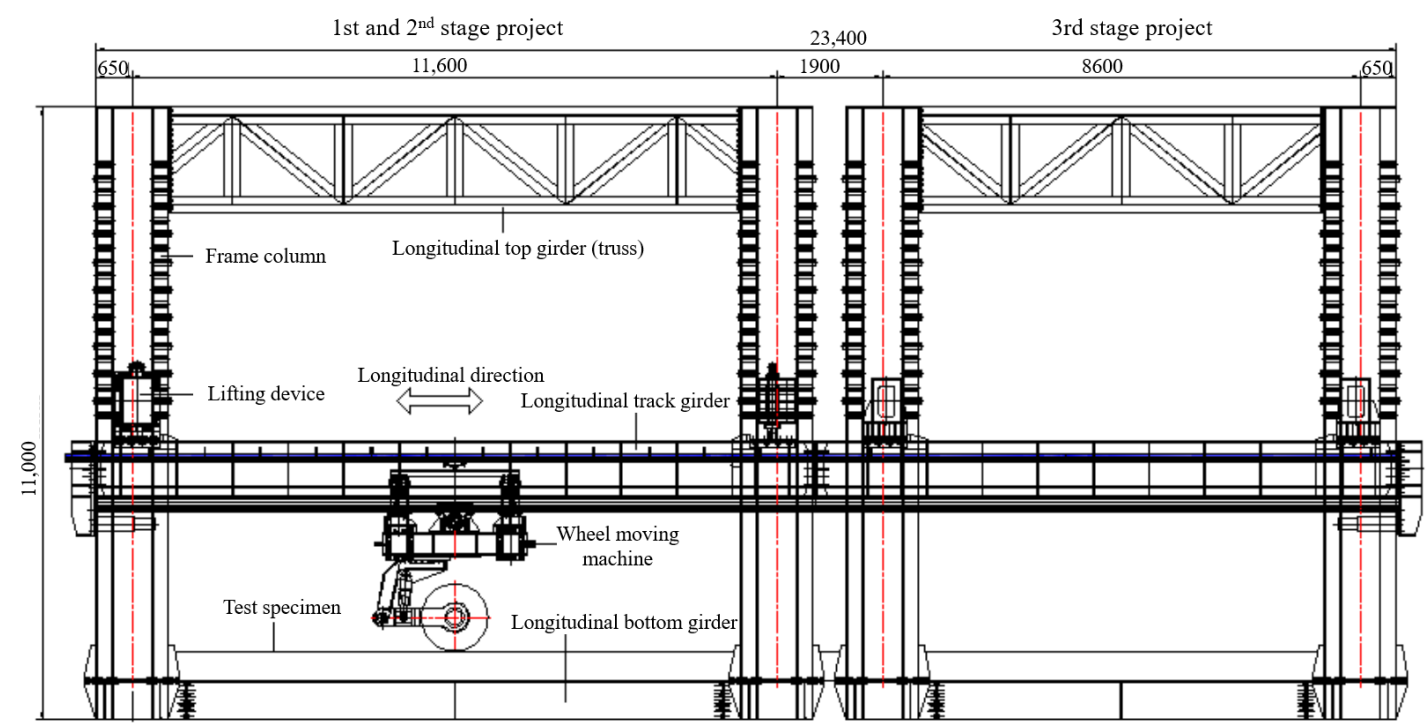

(a) Front view
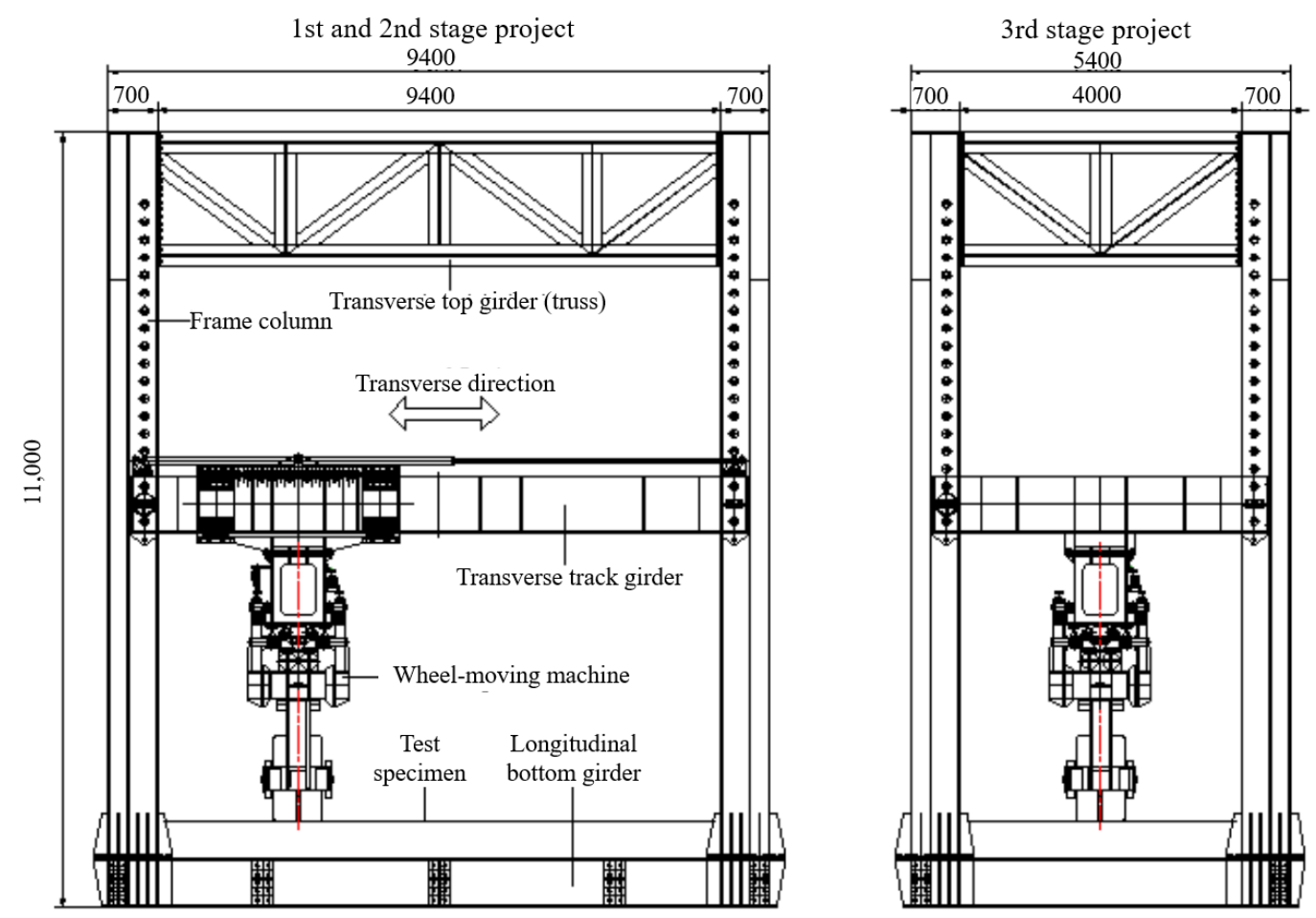

(b) Side view

Figure 7. Drawings of the wheel-moving fatigue test machine (unit: $\mathrm{mm}$ ).

The developed fatigue test machine consisted of a set of hydro-mechatronics devices. The hardware can be divided into five parts: reaction frame, wheel moving machine, lifting and lowering device, electronic control system, and monitoring system. As shown in Figure 7 , the reaction frame was composed of top girders, bottom girders, columns, and track girders. The specimen was placed on the bottom girders. The track girder served as the railway for the moving machine and bore the vertical loads. The electronic control system was composed of a computer, a sensor module, and an operation platform. It was 
used to control the various operations and to provide protection for the security of the test machine. Figure 8 shows the developed wheel-moving fatigue test machine.

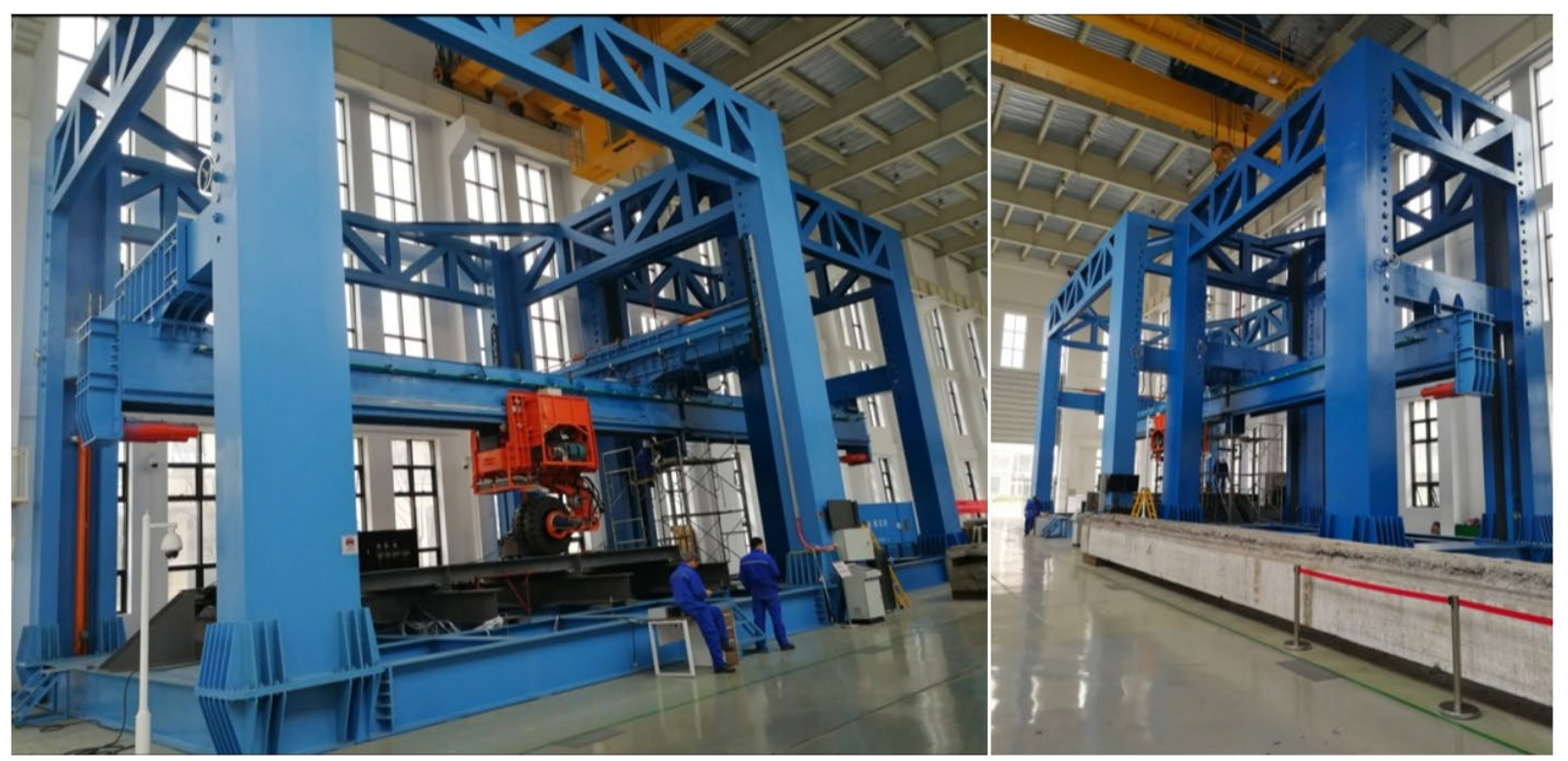

Figure 8. The developed wheel-moving fatigue test machine.

\section{Fatigue Load Test for the CFRP-Strengthened Slab and Result Analysis \\ 3.1. Fatigue Load Cases and Experimental Set-Up}

To investigate the fatigue performance of the CFRP-concrete bonding surface of the CFRP-strengthened hollow slab, this study considered the main traffic loads on the top of the deck, such as the moving loads of vehicles in normal traffic, concentrated loads when vehicles stop on bridges, and impact loads when vehicles accelerate or decelerate. These traffic loads could be simulated by two types of loads when using the developed fatigue test machine: (1) moving load and (2) single point sinusoidal load.

With the as-designed drawings of the original bridge, the lateral load distribution factor was calculated according to actual lane configuration under the most dangerous live load arrangement. Utilizing the calculated load distribution factor, the single beam model, and the equivalent bending moment method and considering the effects of bridge deck overlay, the maximum values of the single point load and moving load were 120 kN under Highway Grade I load case and 90 kN under Highway Grade II load case. The moving range of the moving load was from $0.1 \mathrm{~L}$ to $0.9 \mathrm{~L}$ of the whole tested slab. Here, $L$ represents the total length of the slab, equal to $20 \mathrm{~m}$. The single point load was imposed at the midspan, and the loading followed the sinusoidal curve with the minimum value of 30 $\mathrm{kN}$, maximum values of $90 \mathrm{kN}$ and $120 \mathrm{kN}$, respectively, and frequency of $0.5 \mathrm{~Hz}$. For both the moving loads and the single point sinusoidal load, there were, in total, 200,000 load cycles for the fatigue test. Before conducting the fatigue load test, M15 mortar was used to reduce the roughness of the surface of the slab and better accommodate moving load requirements.

To monitor the structural responses of the hollow slab under fatigue loads, strain gauges and displacement sensors were installed at different locations. As illustrated in Figure 9, the strain gauges were installed in five cross-sections (L1 to L5) of the hollow slab, including the web of the hollow slab and the CFRP layers. L2, L3, and L4 represent the first quarter, midspan and third quarter of the hollow slab. As shown in Figure 10, there were, in total, 15 strain gauges installed in the web at L3 and L4, namely ZR1 to ZR5, ZL1 to ZL5, and F1 to F5. At each location from L1 to L5, two strain gauges were installed on the concrete surface between CFRP A and B, and CFRP B and C, respectively. All these 
strain gauges were distributed uniformly along the vertical section of the web. At each location from L1 to L5, strain gauges were installed on the surfaces of the CFRP layers. As mentioned above, two CFRP layers overlapped in one CFRP strip. Different strain gauges were installed on both layers (CFRP layer 1 and CFRP layer 2). It should be noted that strain gauge installations in CFRP A and C, and D were different, as illustrated in Figure 11. Figure 12 shows the layout of the displacement sensor installation at the bottom of the hollow slab. There were a total of 10 displacement sensors. Figure 13 shows the sensor installation and loading process during the fatigue load test. The measurement range of the strain gauge installed on the surface of the concrete was $2000 \mu \varepsilon$, and the accuracy was $1 \mu \varepsilon$. The measurement range of the strain gauge installed on the surface of the CFRP strips was $15,000 \mu \varepsilon$, and the accuracy was $1 \mu \varepsilon$. The displacement sensor used in this experiment was a laser-type sensor with a resolution of $20 \mu \mathrm{m}$. The measurement center distance was $130 \mathrm{~mm}$ and the measurement range of the displacement sensor was $50 \mathrm{~mm}$.

Dimension unit: $\mathrm{mm}$

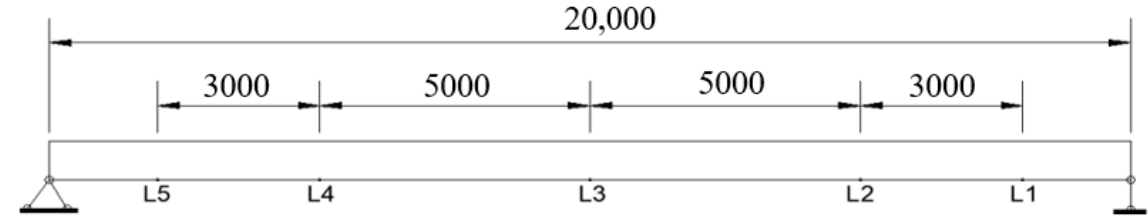

Figure 9. Strain gauge installations along the hollow slab.

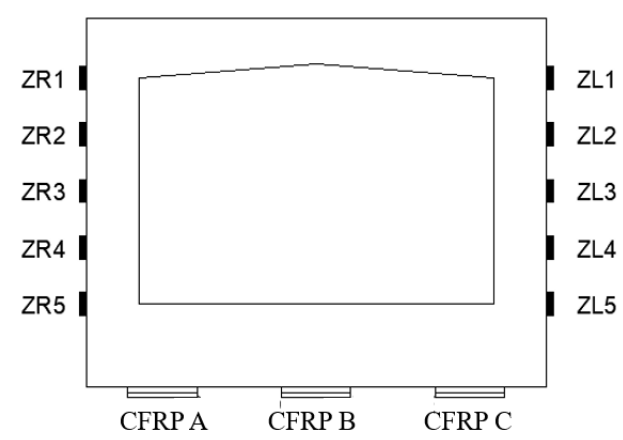

(a) Strain gauge layout on L3

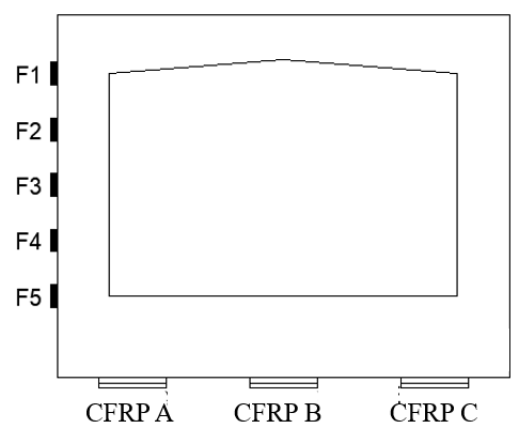

(b) Strain gauge layout on L4

Figure 10. Layout of the strain gauge installation on the web of the hollow slab.

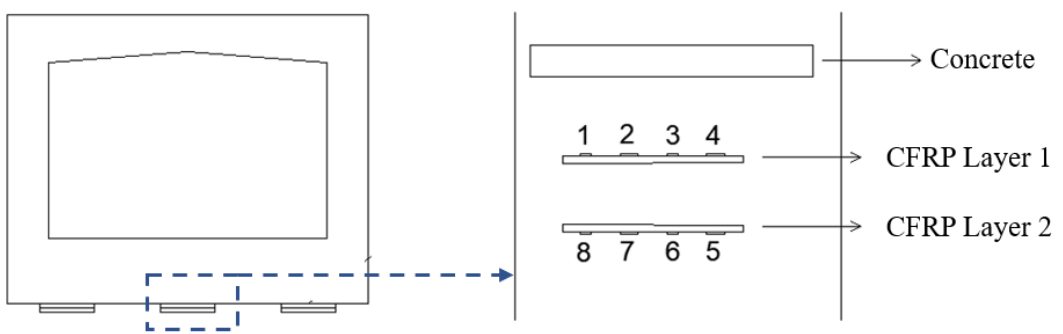

(a) Strain gauge layout of CFRP B

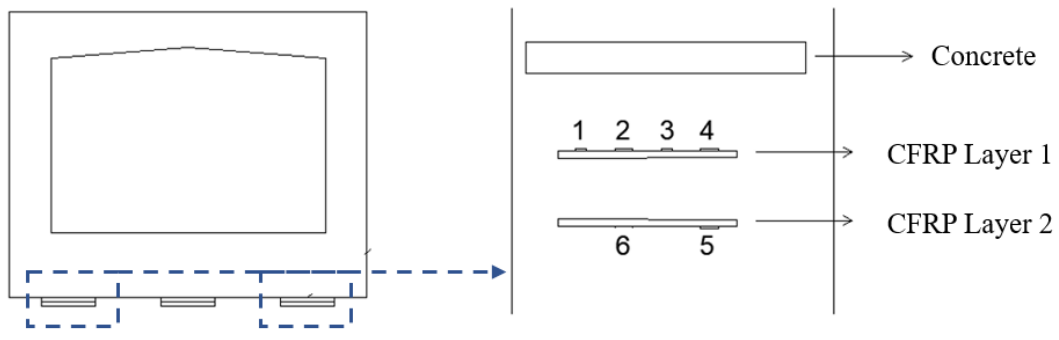

(b) Strain gauge layout of CFRP A and C

Figure 11. Layout of the strain gauge installation on the CFRP layers. 


\begin{tabular}{|llll|} 
Close to bearing section & L4 & Close to bearing section \\
\hline $\mathbf{\square}^{\text {DIS5 }}$ & $\mathbf{m}^{\text {DIS7 } 6}$ & $\mathbf{m}^{\text {DIS3 }}$ & DIS1 \\
\hline
\end{tabular}

Figure 12. Layout of the displacement sensor installation at the bottom of the hollow slab.

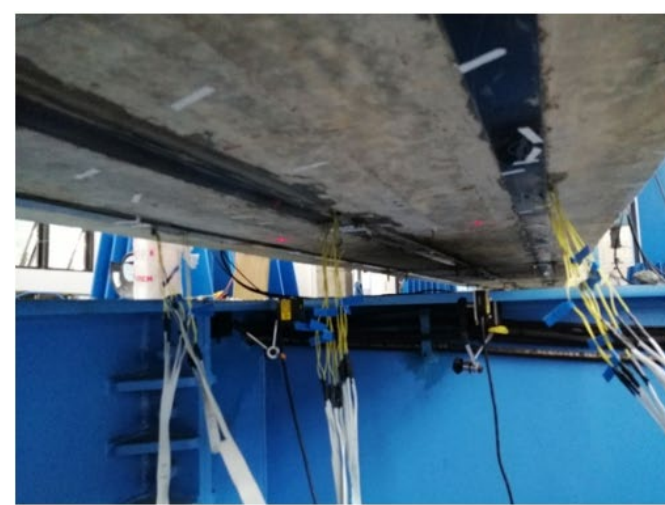

(a) Sensor installation

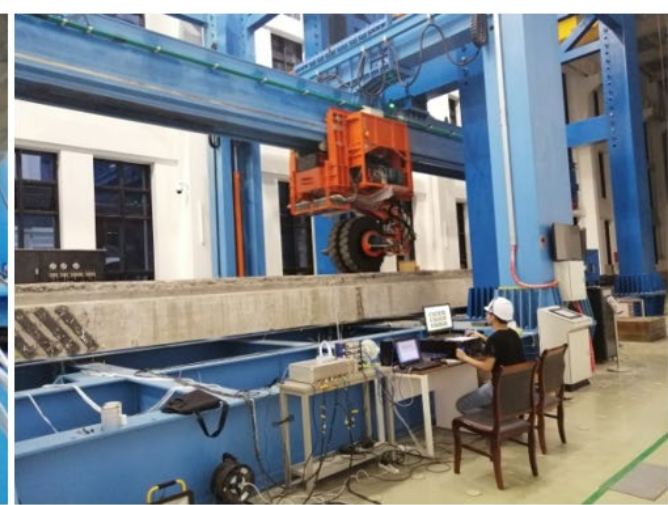

(b) Loading process

Figure 13. Sensor installation and loading process during the fatigue load test.

\subsection{Result Analysis}

\subsubsection{Moving Load Case}

Under the $120 \mathrm{kN}$ moving load, the peak value and range of displacement was stable except for some fluctuations at the very beginning when the test machine was started. Figure 14 shows the selected one-hour displacement time histories of the midspan and $1 / 4$ span $(1 / 4 \mathrm{~L})$ under $120 \mathrm{kN}$ moving load. As shown, at the midspan, the minimum displacement was around $1 / 3$ of the maximum displacement, which was close to the theoretical calculations. Thus, under the $120 \mathrm{kN}$ moving load, the strengthened hollow slab performed well in the elastic range.

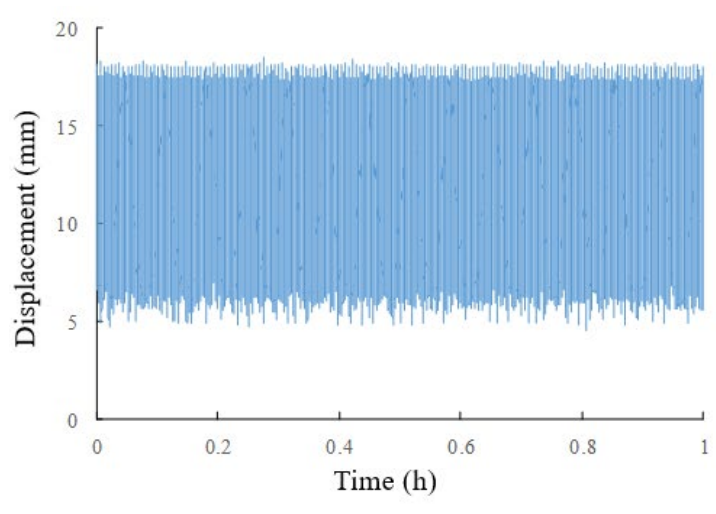

(a) midspan

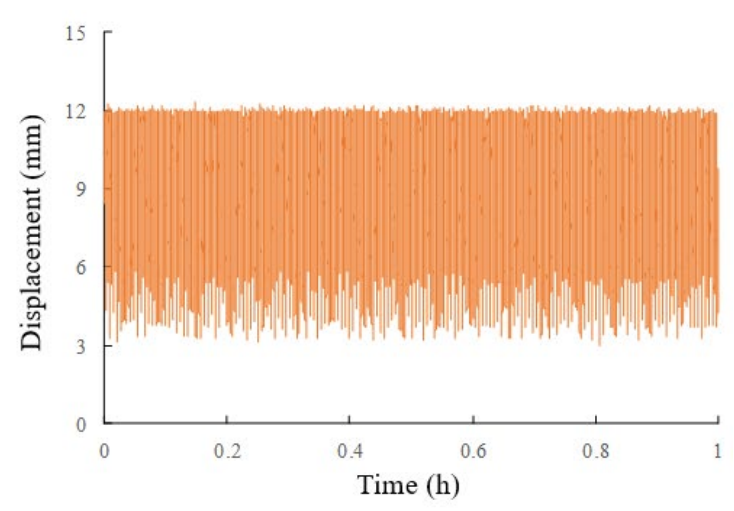

(b) $1 / 4 L$

Figure 14. Displacement time histories of the strengthened hollow slab under $120 \mathrm{kN}$ moving load.

Similar to the displacement time histories, the stain time histories under the moving load also showed stable peaks and ranges. In the same cross-section, strain values in CFRP A and CFRP C were close, but they were smaller than the strain value in CFRP B. Considering the locations of the three CFRP strips, as shown in Figure 10, CFRP B was in the middle and, during the loading process, should have given larger displacement values when the moving load was set in the middle of the slab. Figure 15 gives an example of 
one-hour strain time histories of the CFRP at the midspan of the strengthened hollow slab under $120 \mathrm{kN}$ moving load.

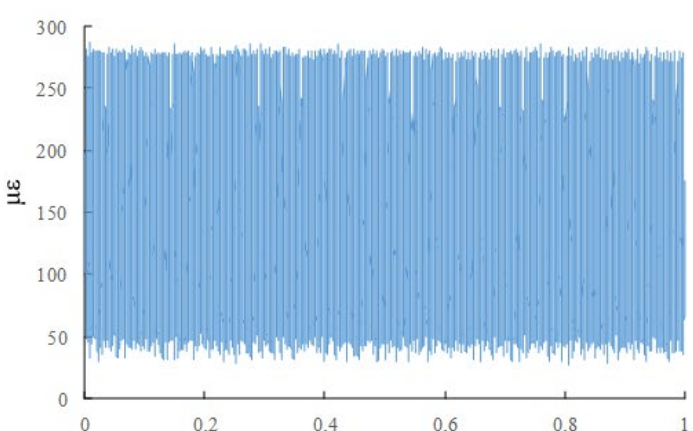

(a) CFRP A

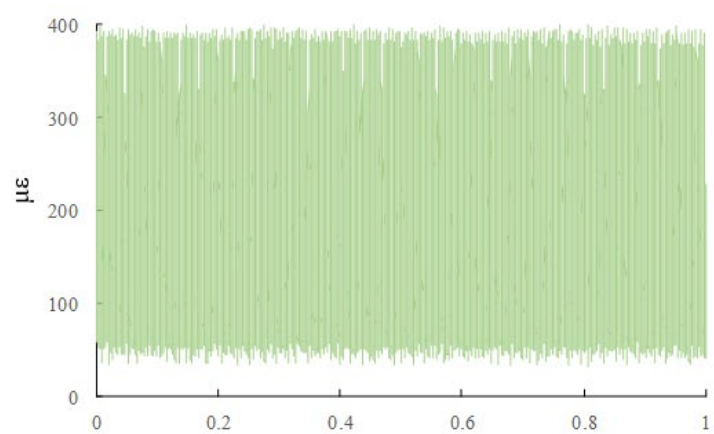

(b) CFRP B

Figure 15. Strain time histories of the CFRP strips on the strengthened hollow slab under $120 \mathrm{kN}$ moving load.

Figure 16 shows the average strain time values of the upper surface and bottom surface of CFRP B under the moving load cycles. The values were calculated by taking the average of strain gauges 1 to 4 on the upper surfaces of CFRP $B$ and strain gauges 5 to 8 on the upper surfaces of CFRP B, as illustrated in Figure 11a. Figure 16 suggests that the stain value on the upper surfaces of the CFRP strip were larger than the bottom surface, meaning that the layer in contact with the concrete experienced greater strain.

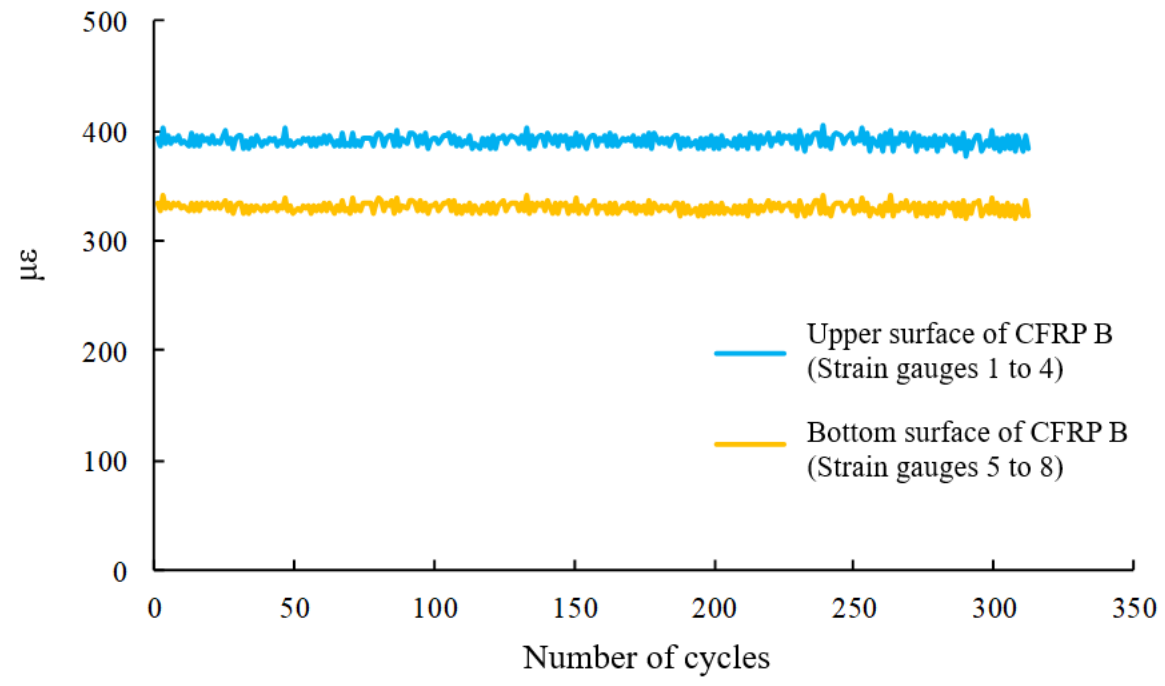

Figure 16. Average strain of the upper surface and bottom surface of CFRP B.

Figure 17 shows the strain distributions along the longitudinal and vertical directions of the strengthened hollow slab. It can be seen that the strain at the bottom of the hollow slab along the longitudinal direction were distributed symmetrically. However, the strain values on the web of the hollow slab along the vertical direction were not distributed uniformly, perhaps because the tension area of the concrete was compressed by the CFRP strips. 


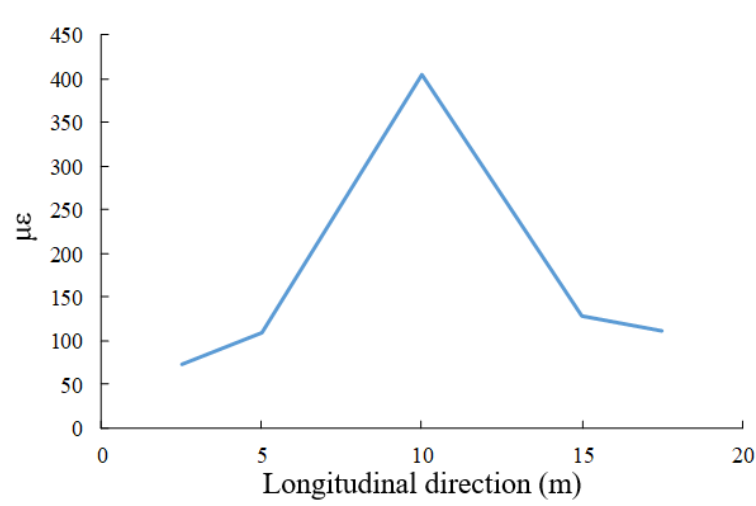

(a)

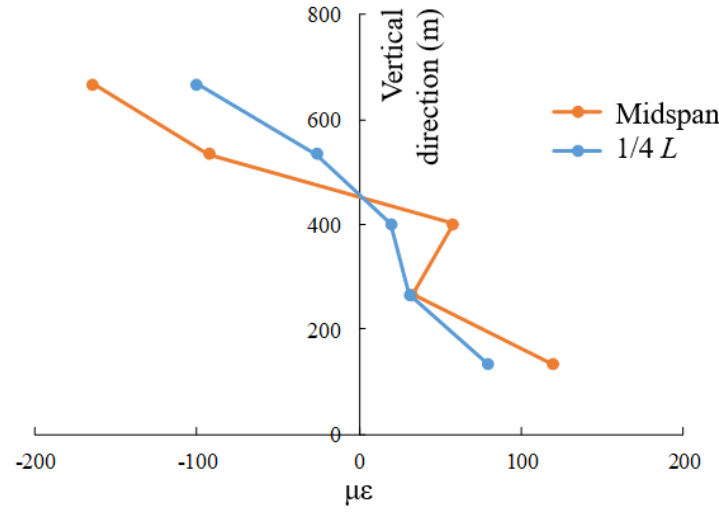

(b)

Figure 17. Strain distributions along the longitudinal and vertical directions of the strengthened hollow slab: (a) strain distribution along the longitudinal direction of the hollow slab; (b) strain distribution along the vertical direction of the hollow slab.

\subsubsection{Single Point Sinusoidal Load Case}

Figure 18 shows the displacement time histories of the strengthened hollow slab under $120 \mathrm{kN}$ single point sinusoidal load. Similar to the moving load case, the displacement time histories under single point sinusoidal load showed stable peaks and ranges, but the shapes were much clearer and smoother than the cases under moving load. Figure 19 gives an example of the strain time histories of the CFRP strips (B and C) on the strengthened hollow slab under $120 \mathrm{kN}$ single point sinusoidal load. Results suggested that the CFRP strip in the middle (CFRP B) had larger strain values than those on the side (CFRP C).

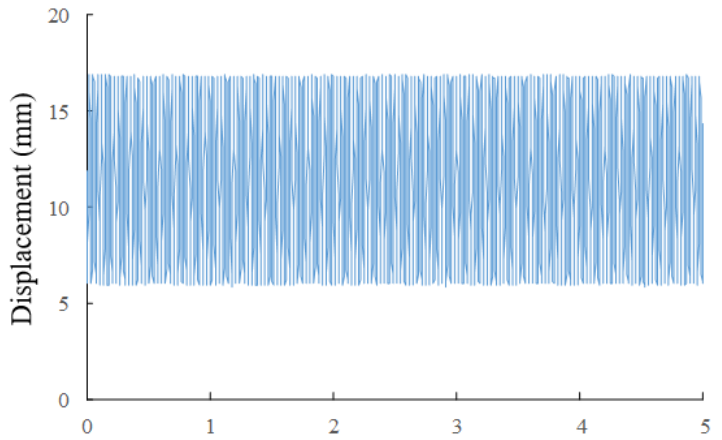

(a) midspan

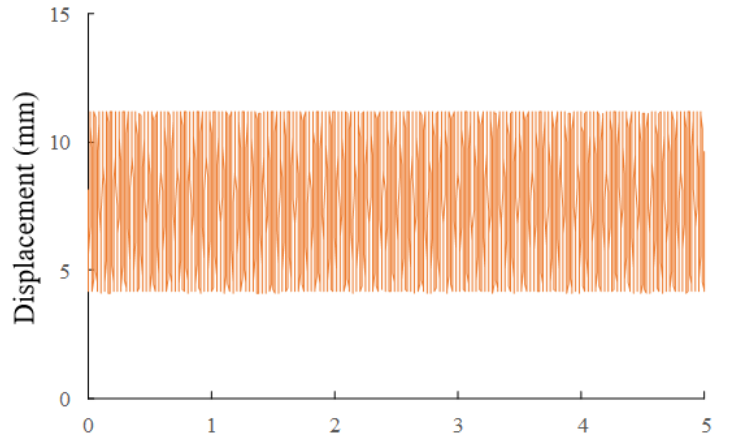

(b) $1 / 4 L$

Figure 18. Displacement time histories of the strengthened hollow slab under $120 \mathrm{kN}$ single point sinusoidal load.

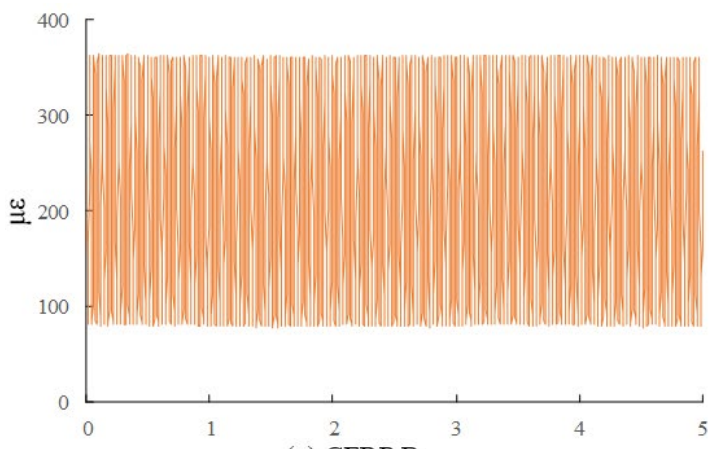

(a) CFRP B

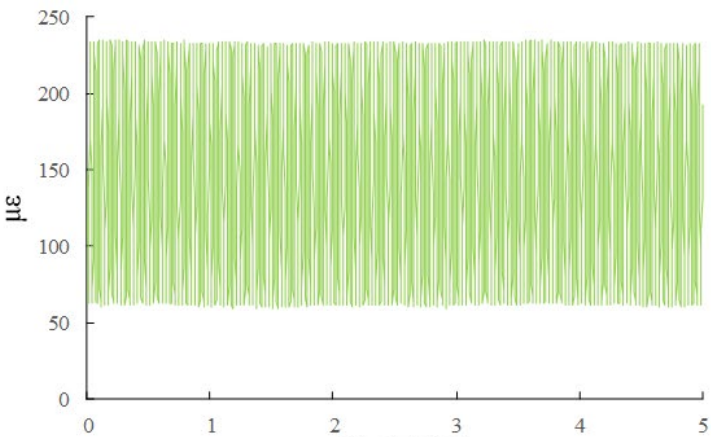

(b) CFRP C

Figure 19. Strain time histories of the CFRP strips on the strengthened hollow slab under $120 \mathrm{kN}$ single point sinusoidal load. 


\subsubsection{Comparisons}

To compare the structural responses of the tested hollow slab strengthened with CFRP strips under moving load and single point sinusoidal load, the midspan displacement and the average peak strain values of the prestressed CFRP strips under $120 \mathrm{kN}$ were calculated, as shown in Table 2. The comparison results indicated that the structural responses caused by the moving loads were generally greater than those caused by single point sinusoidal load, which means that the moving load had greater impact effects on the tested hollow slab. When replacing moving loads with single point loads for fatigue test, it is advisable to increase the upper limit of the fatigue loads. In current research studies and engineering practices, most fatigue tests have been conducted with single point loads. The developed wheel-moving fatigue test machine used in this study provided a better solution to simulate actual fatigue load conditions.

Table 2. Comparison of the midspan displacement and the average peak strain values of the prestressed CFRP strips under $120 \mathrm{kN}$.

\begin{tabular}{cccc}
\hline Items & Load Case & Value & Difference \\
\hline Midspan displacement $(\mathrm{mm})$ & Moving & 17.8 & \multirow{2}{*}{$6.4 \%$} \\
Average peek strain value in CFRP A & Single & 16.7 & $21.3 \%$ \\
$\left(\times 10^{-6}\right)$ & Moving & 278.6 & \\
Average peek strain value in CFRP B & Single & 224.9 & $8.7 \%$ \\
$\left(\times 10^{-6}\right)$ & Moving & 390.8 & $-0.5 \%$ \\
Average peek strain value in CFRP C & Single & 357.9 & \\
$\left(\times 10^{-6}\right)$ & Moving & 230.2 & \\
\hline
\end{tabular}

Table 3 shows the comparison of the midspan displacements of the strengthened hollow slab under Highway Grade I moving load, single point sinusoidal load, static load, and the hollow slab under static load before damage due to the destructive test. Due to the static loading process, the loading status lasted for a specific time in each loading step. Thus, there was enough time for the structural internal force and deformation to reach steady levels. That is why the displacement of the strengthened hollow slab showed larger values under static load than moving load and single point sinusoidal load. Moreover, the displacement of the CFRP-strengthened hollow slab was larger than that observed when the hollow slab was not damaged due to the destructive test. Even though the hollow slab was strengthened with CFRP strips, due to the severe damage, the stiffness of the hollow slab could not be fully recovered under normal operational loads.

Table 3. Comparison of the midspan displacement under Highway Grade I moving load, single point sinusoidal load, static load.

\begin{tabular}{cc}
\hline Load Case & Midspan Displacement (mm) \\
\hline Moving load, after strengthen & 17.8 \\
Single load, after strengthen & 16.7 \\
Static load, after strengthen & 20.1 \\
Static load, before damage & 14.7 \\
\hline
\end{tabular}

\subsubsection{Fatigue Performance Observations in CFRP-Concrete Bonding Surface}

During the entire 200,000 iterations of fatigue load cycles under moving load, the adhesive began to show some white lines as shown in Figure 20, beginning when the load cycles reached 5000. Additionally, with increasing cycles, the number of white lines also increased, while there was no observed fatigue damage in the concrete or rebars of the hollow slab. The white lines in the adhesive were observed at the main crack of the bottom of the original concrete. This indicated that the cracks were opening and closing under the fatigue loads. This resulted in the adhesive repeatedly bending, similar to the 
white lines seen when bending a plastic plate. With the increase of the fatigue loading time, the white lines would keep increasing and be linked to a line along the bottom of the concrete slab. Eventually, a debonding phenomenon would occur in the CFRP-concrete surface, though it would require a great number of fatigue cycles. Overall, with the CFRP strengthening actions, the severely damaged hollow slab could still perform well under normal operational load (Highway Grade I), and the fatigue performance of the CFRPconcrete bonding surface was determined to be able to satisfy real-life operational services in the short term.

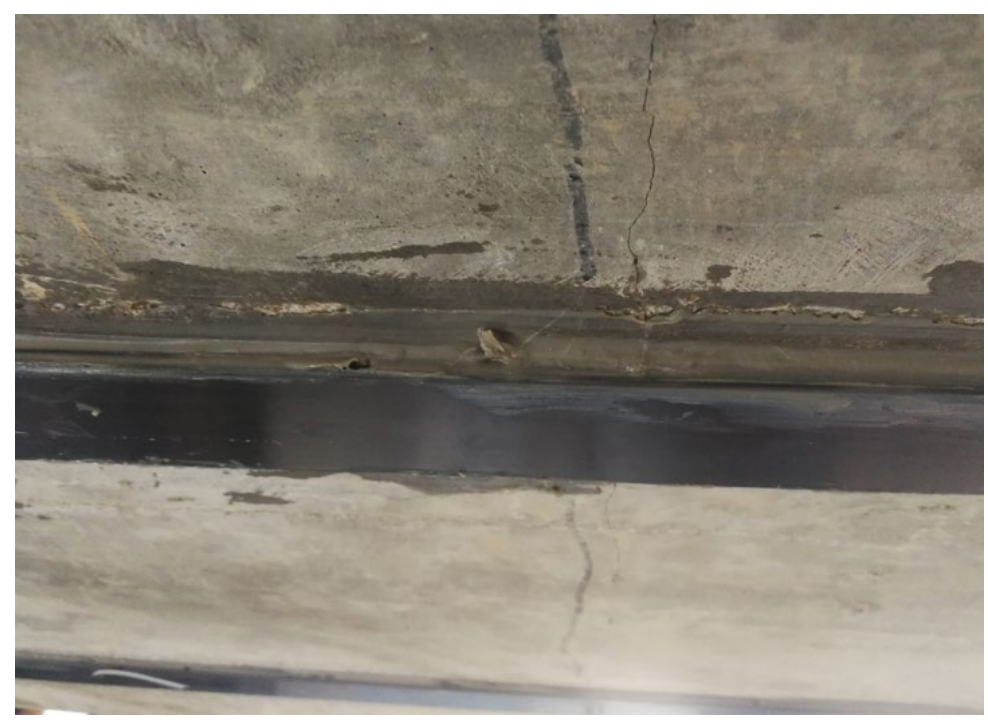

Figure 20. Strain time histories of the CFRP strips on the strengthened hollow slab under $120 \mathrm{kN}$ single point sinusoidal load.

\section{Load-Bearing Capacity Test for the CFRP-Strengthened Slab and Result Analysis 4.1. Load Program and Experimental Set-Up}

After the fatigue load test on the strengthened hollow slab, a load-bearing capacity test was conducted to verify the feasibility of the severely damaged slab (once it was strengthened and repaired using CFRP strips) and investigate the efficiency of the capacity improvement. The experimental set-up for the load-bearing capacity test was the same as that used in the destructive test, as shown in Figure 4. The loading process was controlled by changing the load of the hydraulic jack, $P$. The cracks of the severely damaged slab in the concrete of the pure bending area formed during the destructive test were closed due to the prestress provided by the CFRP strengthening procedure. The theoretical load to compensate for prestressing effects was $118 \mathrm{kN}$. After this compensating load, the concrete began to show cracks again. The planed load path for this load-bearing capacity test was from 0 to $240 \mathrm{kN}$. The load step was $10 \mathrm{kN}$ and, at each load step, the load was held for 5 min to inspect the crack width, crack propagation and CFRP-concrete bonding surface. After $240 \mathrm{kN}$, the load step was $20 \mathrm{kN}$; at each load step, the load was held for $10 \mathrm{~min}$ and the loading process maintained this configuration until severe adhesive failures appeared in the CFRP-concrete surface. During the load test, strain gauges and displacement sensors were installed to monitor structural responses. The sensor layouts were the same as those arranged in the fatigue test.

\subsection{Results Analysis}

\subsubsection{Overall}

Figure 21 shows the comparison of the midspan displacements obtained from the destructive test of the original slab (before damage), the theoretical analysis of the CFRPstrengthened slab (after damage), and the load test of the CFRP-strengthened slab (after damage). The theoretical values of the midspan displacements of the CFRP-strengthened 
slab were calculated based on the load-deflection (displacement) equations. The prestressed CFRP strips were regarded as external prestressed reinforcement. During the loading process, before the decompression point, the bending stiffness for the calculation of displacement was calculated based on the total cross section (with no concrete cracks). After the decompression point, the bending stiffness was calculated based on the cross section with concrete cracks.

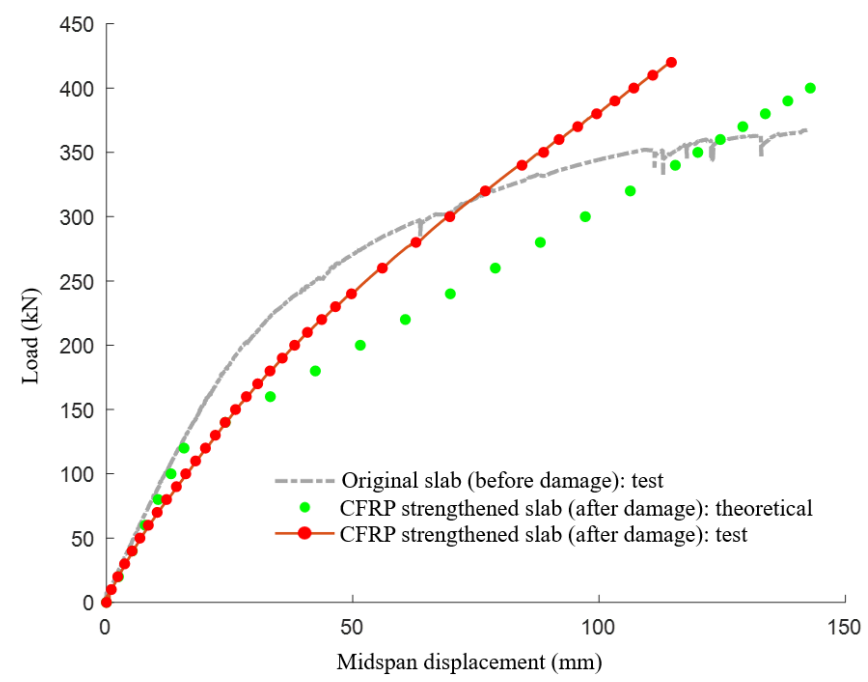

Figure 21. Comparison of the midspan displacements obtained from the destructive test of the original slab (before damage), the theoretical analysis of the CFRP-strengthened slab (after damage), and the load test of the CFRP-strengthened slab (after damage).

From Figure 21, it can be seen that, when the load was smaller than $200 \mathrm{kN}$, the slope of the displacement curve of the original slab during the load test was larger than that of the CFRP-strengthened slab. Accordingly, with the same displacement, the stiffness of the healthy slab (before damage) was larger than the CFRP-strengthened slab. When the load was larger than $200 \mathrm{kN}$, with crack propagation, the concrete lost bearing capacity, and the stiffness of the slab was smaller than the CFRP-strengthened slab. When the load was larger than $300 \mathrm{kN}$, with the same load, the displacement of the original slab during the load test was larger than the CFRP-strengthened slab-and increased rapidly. When the load reached $350 \mathrm{kN}$, the destructive test was stopped, and the original slab was severely damaged. The CFRP-strengthened slab could still be loaded to $420 \mathrm{kN}$, and the displacement was smaller than the value of the destructive test on the original slab when stopped at $350 \mathrm{kN}$. The CFRP-strengthened slab still had bearing capacity and the loading could have been increased; however, taking safety concerns into account and considering the fact that large amounts of adhesive failures had appeared, the test was stopped. It should be noted that, when the load was at $300 \mathrm{kN}$, the midspan displacement was nearly $100 \mathrm{~mm}$, which was the range limit $(50 \mathrm{~mm})$ of the selected laser displacement sensor. A second displacement sensor was used to measure the midspan displacement in the remaining load steps.

From this load-bearing capacity test, it was determined that the prestressed CFRP strengthening approach was able to limit the ultimate deformation of the slab and improve the stiffness of the slab with cracks, compared the original slab without damage. The loadbearing capacity of the CFRP-strengthened slab (after damage) improved by at least $13.5 \%$ compared to the original healthy slab (before damage). This number was slightly lower than the theoretical calculation (18\%) because, in the load test, the CFRP-strengthened slab did not reach the limit of its bearing capacity (due to early test termination).

Because wave-shaped anchors were mounted at the ends of the slab, the failure of the CFRP-strengthened slab lay in adhesive failure in the surface of the concrete and CFRP strips, which caused debonding. Figure 22 shows the adhesive failure process of the 
CFRP-strengthened slab during the load test. When the load was around $280 \mathrm{kN}$, sounds of adhesive failure appeared and the adhesive failure initiated. When the load was 420 $\mathrm{kN}$, large amounts of adhesive failures were observed, but no macro debonding appeared. During the load test, no visible slips happened in the CFRP strips at the locations of the anchors, indicating that the wave-shaped anchor performed reliably.

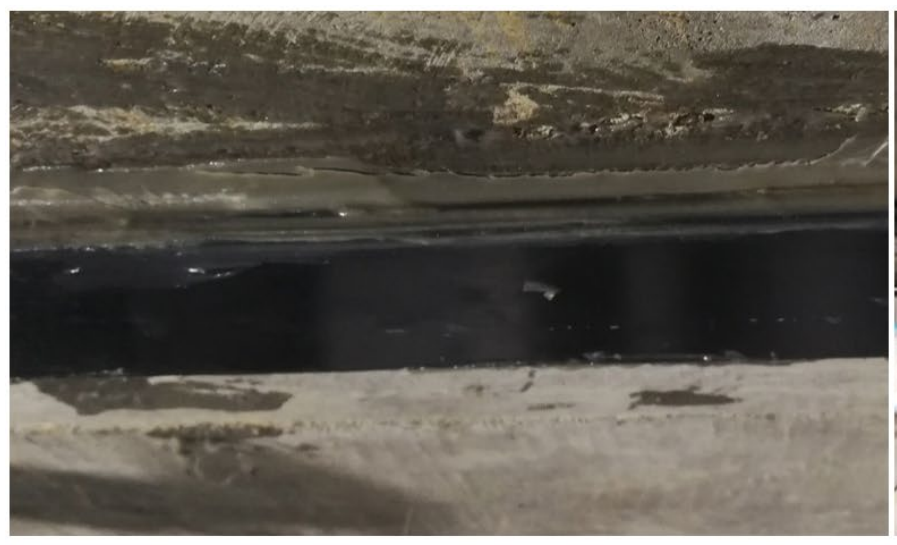

(a)

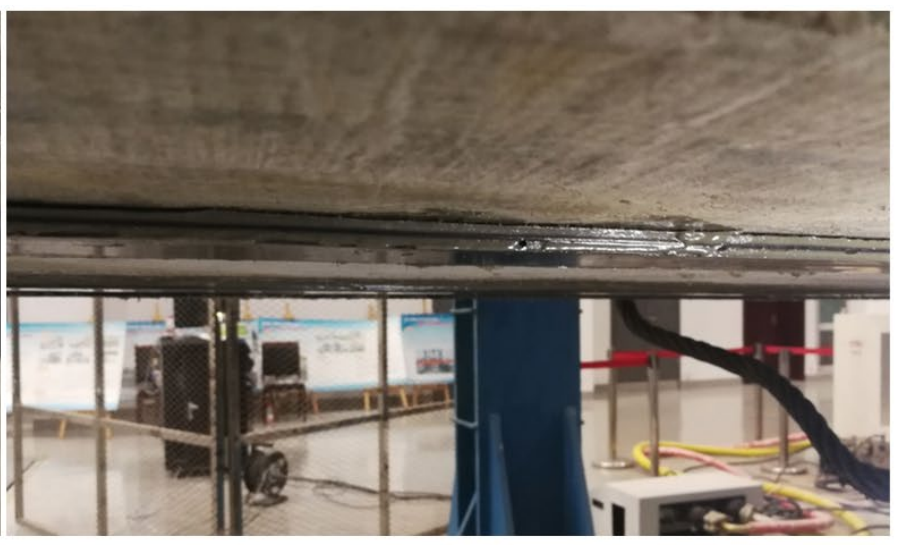

(b)

Figure 22. Adhesive failure process: (a) debonding in CFRP-concrete surface (adhesive failure initiated): $280 \mathrm{kN}$; (b) severe debonding in CFRP-concrete surface (large amounts of adhesive failure): $420 \mathrm{kN}$.

\subsubsection{Analysis of Strain Data}

Figure 23 shows the strain distribution of the CFRP strips along the longitudinal direction during the load test. The strains that occurred at the same time under the same load are connected by colored lines. From the figure, it can be seen that, in all of the CFRP strips-including A, B, C, and the two layers of each strip-the locations with large strain values were in the pure bending section of the slab, i.e., L3 section. However, in the shear-bending sections, i.e., the L1, L2, L4, and L5 sections, the strain values were small. These results signified that the debonding regions of the CFRP strips were mainly in the pure bending section.

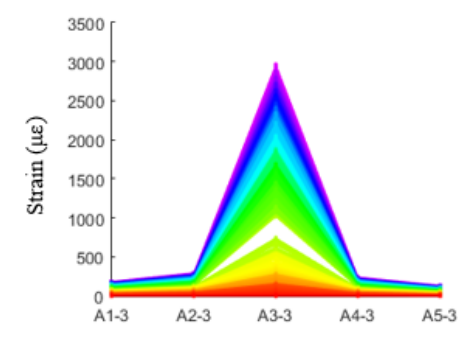

(a) CFRP A, Layer 1

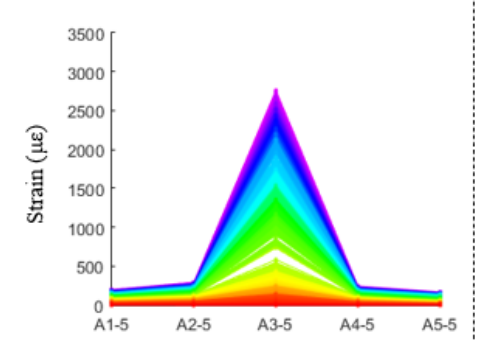

(b) CFRP A, Layer 2

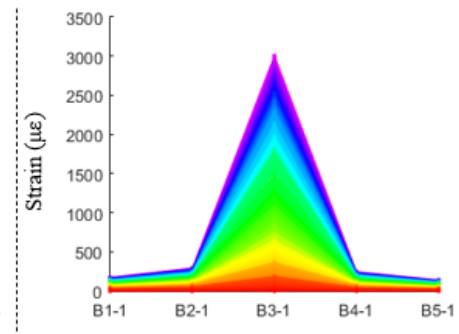

(c) CFRP B, Layer 1

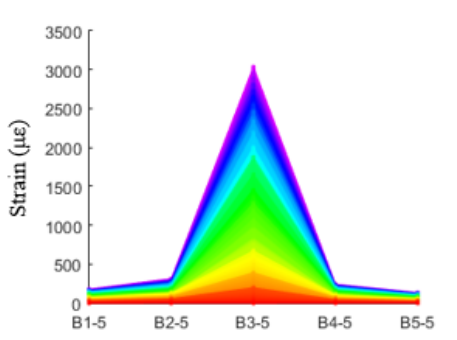

(d) CFRP B, Layer 2

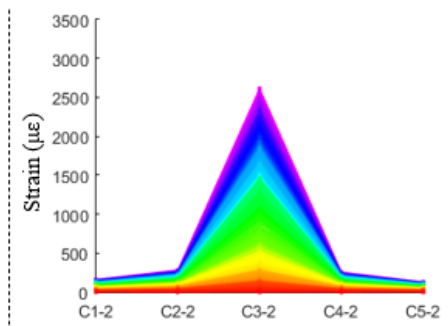

(c) CFRP C, Layer 1

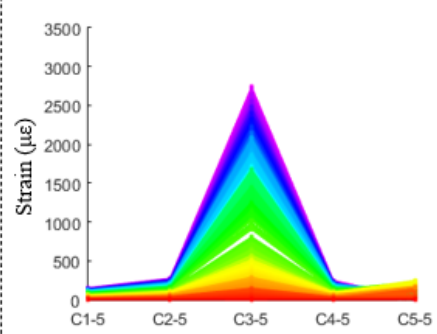

(d) CFRP C, Layer 2

Figure 23. Strain distribution of the CFRP strips along the longitudinal direction. 
Figure 24 shows the strain distribution along the web direction at the midspan of the slab. ZL1 to ZL5 are the measurement points marked in Figure 10a, which were located on the web of the hollow slab. The strains which occurred at the same time (under the same load) along the web direction are connected in the figure using lines of the same respective color. The results indicated that, when the load was small (smaller than $50 \mathrm{kN}$, purple lines in Figure 24), the strain change along the web satisfied the plane section assumption. With increases of the load, the strain change no longer satisfied this assumption. At the end of the load test, the strain at the bottom of the web (ZL5) had a tensile strain of $1100 \mu \varepsilon$, while the strain at the top of the web (ZL1) had a compression strain of $-400 \mu \varepsilon$.

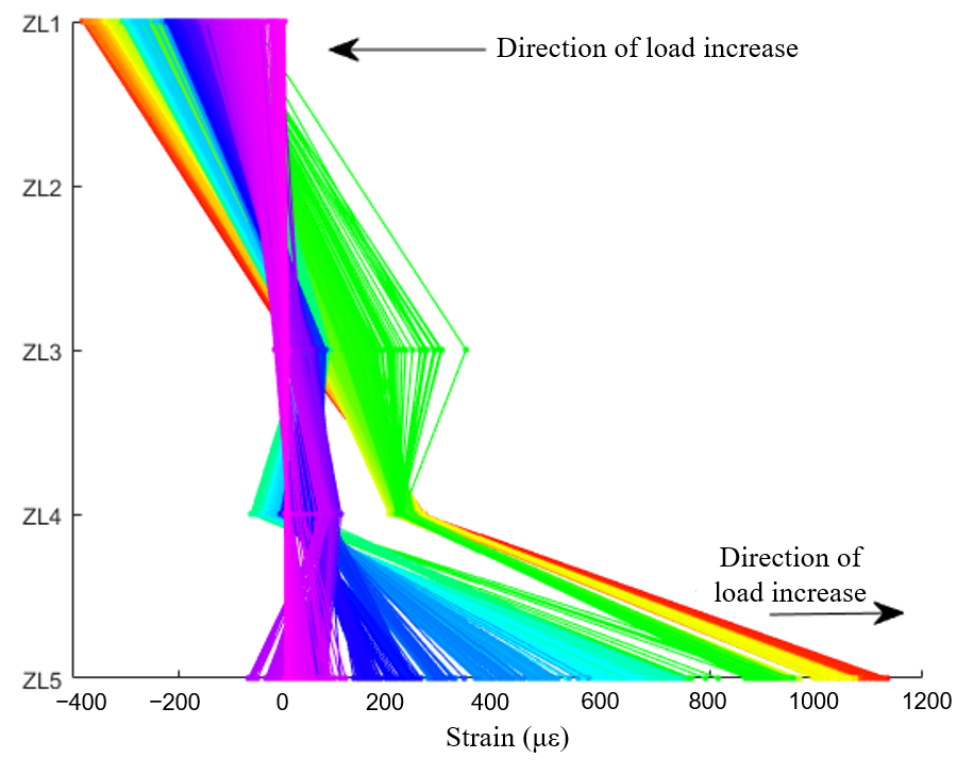

Figure 24. Strain distribution along the web direction at the midspan of the slab.

\subsubsection{Analysis of Cracks}

During the load-bearing capacity test, no new cracks appeared in the CFRP-strengthened hollow slab. The cracks formed during the destructive test are shown in Figure 5a. The crack width changed along the vertical direction of the slab. Three cracks (\#1,\#2 and \#3) were measured during the load test. Figure 25 shows the crack width change and distribution along the vertical direction of the slab. It should be noted that the numbers of the crack width measurement points of the three cracks are different: there are 6 points, 4 points and 3 points uniformly distributed along the three cracks, respectively. As shown in Figure 25, the crack width at the middle section of the slab height was larger than that at the bottom and top section. This was different in the case of the destructive test of the original slab, in which the crack width at the bottom of the slab was larger and decreased towards the top of the slab. This occurred because, in the load test of the CFRP-strengthened slab, the bottom of the slab was constrained by the CFRP strips and crack development was inhibited. This is detailed in the explanatory sketch in Figure 26. When the load was $420 \mathrm{kN}$, and the load test was stopped at that stage, the maximum crack width of the CFRP-strengthened slab was $0.91 \mathrm{~mm}$, much smaller than the crack width of the original slab at the end of the destructive test, $1.53 \mathrm{~mm}$. 


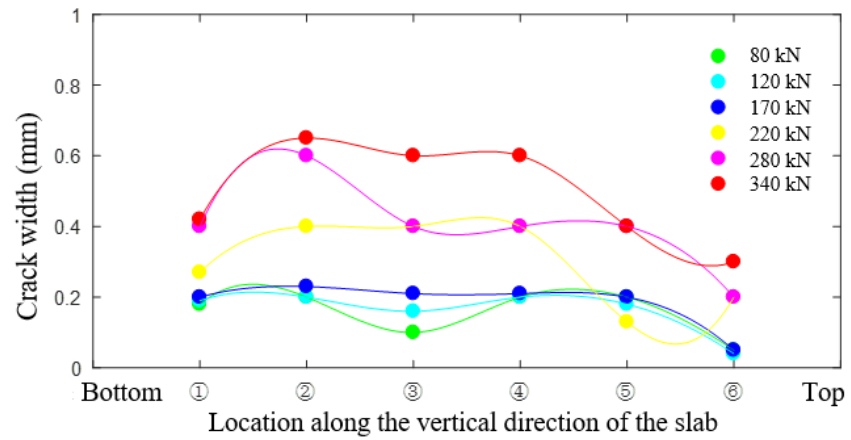

(a) Crack \#1

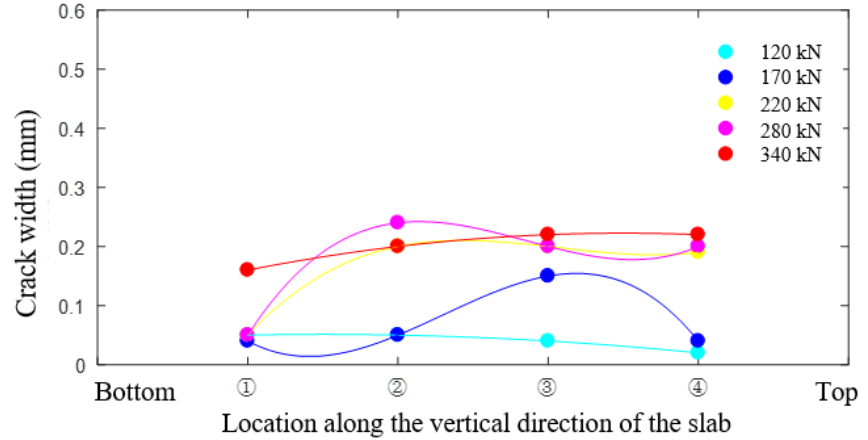

(b) Crack \#2

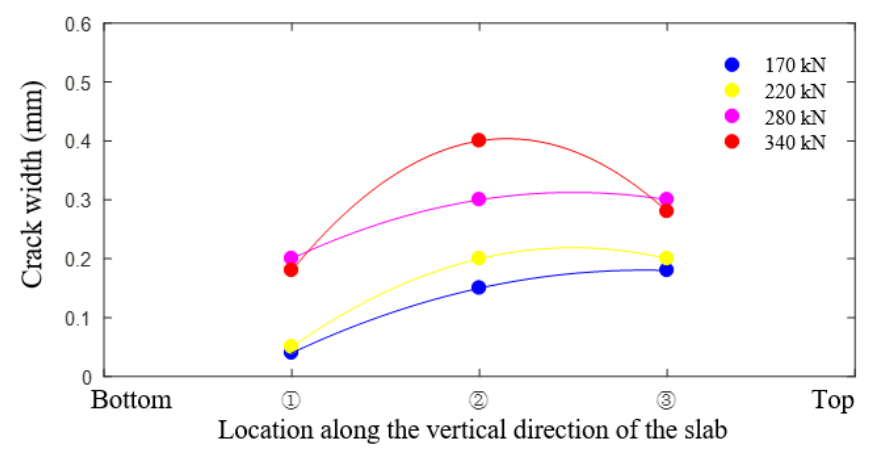

(c) Crack \#3

Figure 25. Crack width change and distribution along the vertical direction of the slab.

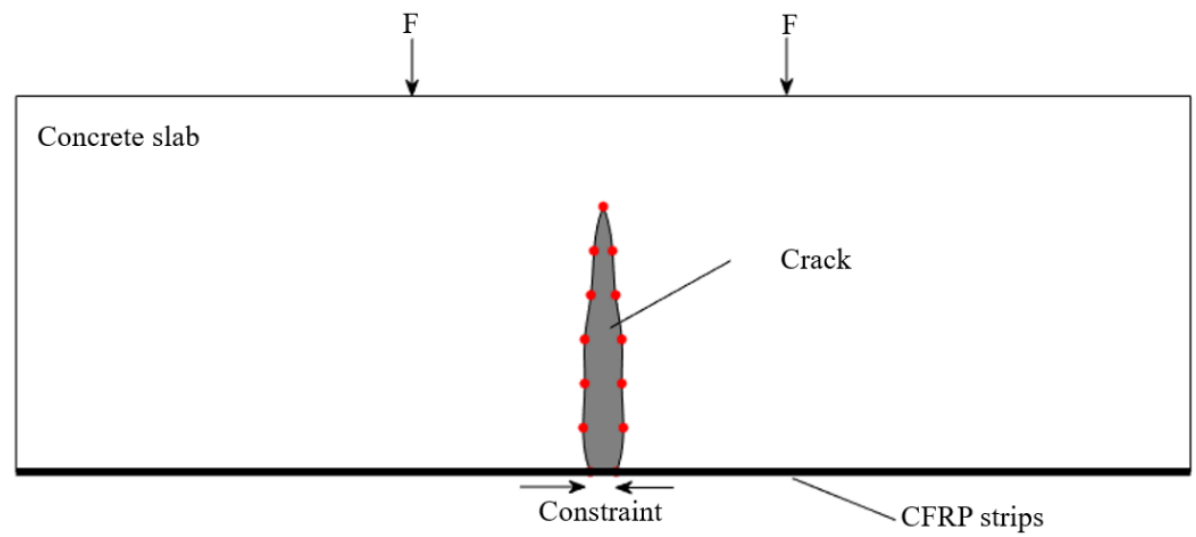

Figure 26. A sketch of the crack development in CFRP-strengthened hollow slab.

\section{Conclusions}

In this study, the feasibility and efficiency of the CFRP strengthening and repair strategy was investigated on a large-scale prestressed concrete hollow slab decommissioned from a concrete bridge. The hollow slab was first put through a destructive test to test its ultimate load-bearing capacity. Then, CFRP strips were installed on the surface of the severely damaged slab to repair and strengthen it. Fatigue load tests and load-bearing capacity tests were conducted on the CFRP-strengthened hollow slab after the destructive test to evaluate the performance of the strengthening measures. Moving load tests and single point sinusoidal load tests were conducted using a specifically developed fatigue test machine which was able to simulate the actual wheel-moving effects. The main findings, observations and conclusions were:

1. The adhesive failure and debonding effects were investigated using the fatigue load test on the CFRP-strengthened hollow slab. The CFRP-concrete surface began to show some white lines when the load cycles reached 5000 iterations. Additionally, with 
increasing cycles, the number of white lines also increased. There was no fatigue damage in the concrete and rebars of the hollow slab.

2. With the CFRP strengthening, the severely damaged hollow slab was still able to perform well under normal operational load (Highway Grade I). Additionally, the fatigue performance of the CFRP-concrete bonding surface was able to satisfy realworld operational service requirements in the short term.

3. Structural responses caused by moving loads were generally larger than those caused by single point sinusoidal loads. These results demonstrate that moving loads had a greater impact on the tested hollow slab. Therefore, when replacing moving loads with single point loads for fatigue testing, it is recommended to increase the upper limit of the fatigue loads.

4. The load-bearing capacity of the CFRP-strengthened slab (after damage) was improved by at least $13.5 \%$ compared to the original healthy slab (before damage).

5. During the load-bearing capacity test, no new cracks appeared in the CFRP-strengthened hollow slab. The crack width at the middle section of the slab height was larger than at the bottom and top sections. In the CFRP-strengthened slab, the bottom of the slab was constrained by the CFRP strips, and crack development was inhibited.

This study provided a detailed experimental program and approach for the investigation of the feasibility and efficiency of CFRP strengthening and repair of large-scale concrete structures. The results could help others to understand the actual load-bearing capacities of severely damaged concrete structures strengthened by CFRP, reduce waste, save resources, and improve the utilization of infrastructures. The present study can thus contribute to and better support sustainable societal and economic developments in Industry 4.0.

Author Contributions: Conceptualization, H.H.; methodology, H.H. and J.C.; software, C.-Z.D., J.W. and J.C.; validation, H.H., C.-Z.D., J.W. and J.C.; formal analysis, C.-Z.D. and J.C.; investigation, H.H. and J.C.; resources, H.H.; data curation, J.C.; writing-original draft preparation, C.-Z.D.; writing-review and editing, H.H., J.W. and J.C.; visualization, C.-Z.D., J.W. and J.C.; supervision, H.H.; project administration, H.H.; funding acquisition, H.H. All authors have read and agreed to the published version of the manuscript.

Funding: This research was funded by Project of Natural Science Foundation of Zhejiang Province (LQY18E080002), Project of Science and Technology of Department of Transportation, Zhejiang Province (2019048), and Science and Technology Innovation Project of Zhejiang Scientific Research Institute of Transport (ZK202102).

Institutional Review Board Statement: Not applicable.

Informed Consent Statement: Not applicable.

Data Availability Statement: The data presented in this study are available on request from the corresponding author.

Acknowledgments: The authors would like to acknowledge the supports of Project of Natural Science Foundation of Zhejiang Province (LQY18E080002), Project of Science and Technology of Department of Transportation, Zhejiang Province (2019048), and Science and Technology Innovation Project of Zhejiang Scientific Research Institute of Transport (ZK202102).

Conflicts of Interest: The authors declare no conflict of interest.

\section{References}

1. Dong, C.Z.; Bas, S.; Catbas, F.N. A portable monitoring approach using cameras and computer vision for bridge load rating in smart cities. J. Civ. Struct. Health Monit. 2020, 10, 1001-1021. [CrossRef]

2. American Society of Civil Engineers. 2021 Report Card for America's Infrastructure; American Society of Civil Engineers: Reston, VA, USA, 2021.

3. Di, J.; Sun, Y.; Yu, K.; Liu, L.; Qin, F. Experimental investigation of shear performance of existing PC hollow slab. Eng. Struct. 2020, 211, 110451. [CrossRef]

4. Dong, C.Z.; Bas, S.; Debees, M.; Alver, N.; Catbas, F.N. Bridge load testing for identifying live load distribution, load rating, serviceability and dynamic response. Front. Built Environ. 2020, 6, 46. [CrossRef] 
5. Dong, C.Z.; Catbas, F.N. A review of computer vision-based structural health monitoring at local and global levels. Struct. Health Monit. 2020, 20, 692-743. [CrossRef]

6. Jin, H.; Jiang, H.; Jiang, R.; Zhan, H.; Xu, Y. Strengthening hollow core concrete bridges with deficient transverse hinge joints with a steel and concrete composite anchorage system. Transp. Res. Rec. 2020, 2674, 68-78. [CrossRef]

7. Wang, S.C.; Wang, C.S.; Wang, Q.; Tian, X.F. Full-scale experimental validation of the steel plate- prestressed concrete composite method for the strengthening of hollow slab girders. Life-Cycle Civ. Eng. Innov. Theory Pract. 2021, 924-930.

8. Zulkifli, S.N.I.; Hisbany, M.H.M.; Ismail, R.; Zakwan, F.A.A.; Hazrina, A.; Ismail, B.N.; Rashid, R.S.M. Application of shape memory alloys (SMA) as a retrofit and strengthening component on reinforced concrete columns: Review Paper. J. Phys. Conf. Ser. 2020, 1529, 042104. [CrossRef]

9. Zhao, H.; Andrawes, B. Local strengthening and repair of concrete bridge girders using shape memory alloy precast prestressing plate. J. Intell. Mater. Syst. Struct. 2020, 31, 1343-1357. [CrossRef]

10. Harajli, M.; Khairallah, N.; Nassif, H. Externally prestressed members: Evaluation of second-order effects. J. Struct. Eng. 1999, 125, 1151-1161. [CrossRef]

11. Tan, K.H.; Tjandra, R.A. Strengthening of RC continuous beams by external prestressing. J. Struct. Eng. 2007, 133, 195-204. [CrossRef]

12. Teng, J.G.; Chen, J.F.; Smith, S.T.; Lam, L. Behaviour and strength of FRP-strengthened RC structures: A state-of-the-art review. Proc. Inst. Civ. Eng. Struct. Build. 2003, 156, 51-62. [CrossRef]

13. Al-Salih, H.; Bennett, C.; Matamoros, A. Evaluation of novel combined CFRP-steel retrofit for repairing distortion-induced fatigue. J. Constr. Steel Res. 2021, 182, 106642. [CrossRef]

14. Heydarinouri, H.; Nussbaumer, A.; Motavalli, M.; Ghafoori, E. Strengthening of steel connections in a 92-year-old railway bridge using prestressed CFRP rods: Multiaxial fatigue design criterion. J. Bridg. Eng. 2021, 26, 04021023. [CrossRef]

15. Beneberu, E.; Yazdani, N. Performance of CFRP-strengthened concrete bridge girders under combined live load and hydrocarbon fire. J. Bridge Eng. 2018, 23, 04018042. [CrossRef]

16. Radhi, M.S.; Hassan, M.S.; Gorgis, I.N. Carbon fibre-reinforced polymer confinement of corroded circular concrete columns. J. Build. Eng. 2021, 43, 102611. [CrossRef]

17. Pelà, L.; Aprile, A.; Benedetti, A. Experimental study of retrofit solutions for damaged concrete bridge slabs. Compos. Part B Eng. 2012, 43, 2471-2479. [CrossRef]

18. Ghous Sohail, M.; Al Nuaimi, N.; Hawileh, R.A.; Abdalla, J.A.; Douier, K. Durability of plain concrete prism strengthened with galvanized steel mesh and CFRP laminates under harsh environmental conditions. Constr. Build. Mater. 2021, 286, 15-19. [CrossRef]

19. Siddika, A.; Al Mamun, M.A.; Ferdous, W.; Alyousef, R. Performances, challenges and opportunities in strengthening reinforced concrete structures by using FRPs-A state-of-the-art review. Eng. Fail. Anal. 2020, 111, 104480. [CrossRef]

20. Lee, L.S.; Jain, R. The role of FRP composites in a sustainable world. Clean Technol. Environ. Policy 2009, 11, 247-249. [CrossRef]

21. Siwowski, T.; Piatek, B.; Siwowska, P.; Wiater, A. Development and implementation of CFRP post-tensioning system for bridge strengthening. Eng. Struct. 2020, 207, 110266. [CrossRef]

22. Farrokh Ghatte, H. External steel ties and CFRP jacketing effects on seismic performance and failure mechanisms of substandard rectangular RC columns. Compos. Struct. 2020, 248, 112542. [CrossRef]

23. Farrokh Ghatte, H.; Comert, M.; Demir, C.; Akbaba, M.; Ilki, A. Seismic retrofit of full-scale substandard extended rectangular RC columns through CFRP jacketing: Test results and design recommendations. J. Compos. Constr. 2019, 23, 04018071. [CrossRef]

24. Pham, T.M.; Hao, H. Review of concrete structures strengthened with FRP against impact loading. Structures 2016, 7, 59-70. [CrossRef]

25. Buyukozturk, O.; Gunes, O.; Karaca, E. Progress on understanding debonding problems in reinforced concrete and steel members strengthened using FRP composites. Constr. Build. Mater. 2004, 18, 9-19. [CrossRef]

26. Buyukozturk, O.; Hearing, B. Failure behavior of precracked concrete beams retrofitted with FRP. J. Compos. Constr. 1998, 2, 138-144. [CrossRef]

27. Yao, J.; Teng, J.G.; Lam, L. Experimental study on intermediate crack debonding in FRP-strengthened RC flexural members. Adv. Struct. Eng. 2005, 8, 365-395. [CrossRef]

28. Al-Ghrery, K.; Al-Mahaidi, R.; Kalfat, R.; Oukaili, N.; Al-Mosawe, A. Experimental investigation of curved-soffit RC Bridge girders strengthened in flexure using CFRP composites. J. Bridg. Eng. 2021, 26, 04021009. [CrossRef]

29. Kotynia, R.; Walendziak, R.; Stoecklin, I.; Meier, U. RC slabs strengthened with prestressed and gradually anchored CFRP strips under monotonic and cyclic loading. J. Compos. Constr. 2011, 15, 168-180. [CrossRef]

30. Cai, J.; Hao, H.; Ozbakkaloglu, T.; Zhang, Y.; Pan, J. Behavior of geopolymeric recycled aggregate concrete-filled FRP tube (GRACFFT) columns under lateral cyclic loading. Eng. Struct. 2020, 222, 111047. [CrossRef]

31. Yao, J.; Teng, J.G. Plate end debonding in FRP-plated RC beams-I: Experiments. Eng. Struct. 2007, 29, 2457-2471. [CrossRef]

32. Teng, J.G.; Yao, J. Plate end debonding in FRP-plated RC beams-II: Strength model. Eng. Struct. 2007, 29, 2472-2486. [CrossRef]

33. Yoshitake, I.; Hasegawa, H.; Shimose, K. Monotonic and cyclic loading tests of reinforced concrete beam strengthened with bond-improved carbon fiber reinforced polymer (CFRP) rods of ultra-high modulus. Eng. Struct. 2020, 206, 110175. [CrossRef]

34. Alam, M.S.; Sultana, N.; Hossain, S.M.Z. Bayesian optimization algorithm based support vector regression analysis for estimation of shear capacity of FRP reinforced concrete members. Appl. Soft Comput. 2021, 105, 107281. [CrossRef] 
35. Saadah, M.; Ashteyat, A.; Murad, Y. Shear strengthening of RC beams using side near surface mounted CFRP ropes and strips. Structures 2021, 32, 380-390. [CrossRef]

36. Teng, J.G.; Chen, G.M.; Chen, J.F.; Rosenboom, O.A.; Lam, L. Behavior of RC beams shear strengthened with bonded or unbonded FRP wraps. J. Compos. Constr. 2009, 13, 394-404. [CrossRef]

37. Peng, H.; Zhang, J.; Cai, C.S.; Liu, Y. An experimental study on reinforced concrete beams strengthened with prestressed near surface mounted CFRP strips. Eng. Struct. 2014, 79, 222-233. [CrossRef]

38. Triantafillou, T.; Deskovic, N.; Deuring, M. Strengthening of concrete structures with prestressed FRP sheets. ACI Struct. J. 1992, 89, 235-244.

39. Quantrill, R.J.; Hollaway, L.C. The flexural rehabilitation of reinforced concrete beams by the use of prestressed advanced composite plates. Compos. Sci. Technol. 1998, 58, 1259-1275. [CrossRef]

40. Wight, R.G.; Green, M.F.; Erki, M.A. Prestressed FRP sheets for poststrengthening reinforced concrete beams. J. Compos. Constr. 2001, 5, 214-220. [CrossRef]

41. Moshiri, N.; Czaderski, C.; Mostofinejad, D.; Hosseini, A.; Sanginabadi, K.; Breveglieri, M.; Motavalli, M. Flexural strengthening of RC slabs with nonprestressed and prestressed CFRP strips using EBROG method. Compos. Part B Eng. 2020, 201, 108359. [CrossRef]

42. Chalot, A.; Michel, L.; Ferrier, E. Experimental study of external bonded CFRP-concrete interface under low cycle fatigue loading Compos. Part B Eng. 2019, 177, 107255. [CrossRef]

43. Zhou, H.; Fernando, D.; Thuan Nguyen, V.; Dai, J.G. The bond behaviour of CFRP-to-concrete bonded joints under fatigue cyclic loading: An experimental study. Constr. Build. Mater. 2021, 273, 121674. [CrossRef]

44. CABR. Code for Acceptance of Constructional Quality of Concrete Structures, 2015th ed.; GB 50204-2015; China Architecture \& Building Press: Beijing, China, 2015. 